\title{
The Neotropical species of Clistopyga (Hymenoptera, Ichneumonidae, Pimplinae). Part I: the $C$. chaconi species group, with the description of eleven new species
}

\author{
Santiago BORDERA ${ }^{1, *}$, Ilari Eerikki SÄÄKSJÄRVI ${ }^{2}$, Carol CASTILLO ${ }^{3}$, \\ Edgard PALACIO ${ }^{4} \&$ Alejandra GONZÁLEZ-MORENO ${ }^{5}$ \\ ${ }^{1}$ Departamento de Ciencias Ambientales y Recursos Naturales \& Instituto de Investigación CIBIO \\ (Centro Iberoamericano de Biodiversidad), \\ Universidad de Alicante, Apdo. Corr. 99, 03080. Alicante, Spain. \\ 2,3 Zoological Museum, Department of Biology, University of Turku, FI-20014 Finland. \\ ${ }^{4}$ Instituto Colombiano Agropecuario (ICA), Calle 18 N ${ }^{\circ}$ 50-32 Soledad, Barranquilla, Colombia. \\ ${ }^{5}$ Instituto Tecnológico de Conkal, Km 16.3 antigua carretera Merida-Motul, \\ C.P. 97345, Conkal, Yucatán, México. \\ *Corresponding author: s.bordera@ua.es \\ 2 Email: ileesa@utu.fi \\ ${ }^{3}$ Email: hedonazur@yahoo.com \\ ${ }^{4}$ Email: itoplectis@gmail.com \\ ${ }^{5}$ Email: gonzalezmoreale@gmail.com

\footnotetext{
${ }^{1}$ urn:1sid:zoobank.org:author:CE4BC30D-26D7-4F70-BAAC-3A6FBDF49AFD

${ }^{2}$ urn:1sid:zoobank.org:author:2B80E7A4-FEA6-4493-80C1-5B28FB0CDB8F

${ }^{3}$ urn:lsid:zoobank.org:author:5BCF7981-1803-40E0-8149-884AD2CCA525

${ }^{4}$ urn:1sid:zoobank.org:author:BE4BF24C-B427-48C3-B572-7EAB7F3610AE

${ }^{5}$ urn:lsid:zoobank.org:author:FF411FA9-D581-4E5E-BD8D-E396BAA356A7
}

\begin{abstract}
The New World Clistopyga chaconi species group is revised. Eleven species are described as new: C. amazonica sp. nov., C. cinnamoptera sp. nov., C. cuscoensis sp. nov., C. hayesiana sp. nov., C. melanoptera sp. nov., C. misionensis sp. nov., C. mocaguae sp. nov., C. orellanae sp. nov., C. porteri sp. nov., C. rondoniae sp. nov. and C. yabuquensis sp. nov. Additional morphological data are provided for the previously known species, C. caramba Castillo \& Sääksjärvi and C. chaconi Gauld. An illustrated identification key to all species of the group is provided. The Clistopyga chaconi species group appears to be most diverse at the Andean and Amazonian interface in western South America.
\end{abstract}

Key words. Neotropic, taxonomy, parasitoid wasps, new species, key.

Bordera S., Sääksjärvi I.E., Castillo C., Palacio E. \& González-Moreno A. 2016. The Neotropical species of Clistopyga (Hymenoptera, Ichneumonidae, Pimplinae). Part I: the $C$. chaconi species group, with the description of eleven new species. European Journal of Taxonomy 206: 1-37. http://dx.doi.org/10.5852/ejt.2016.206 


\section{Introduction}

Clistopyga Gravenhorst, 1829 (Hymenoptera: Ichneumonidae) is a moderately large pimpline genus, comprising currently 38 described species (Yu et al. 2012; Bordera et al. 2014; Sääksjärvi et al. 2015; Varga \& Reshchikov 2015), of which 2 have been recorded from the Afrotropical region, 3 from the Oriental region and 9 from the Palaearctic region. However, the genus is most species-rich in the New World where 19 species have been reported from North America (including Mexico) and 16 species from Central and South America. In addition, a large number of undescribed species are known to occur in South America (Gauld 1991; Sääksjärvi et al. 2015). According to our unpublished data, the genus seems to be especially rich at the Andean and Amazonian interface.

Most Clistopyga species are rarely observed or collected and thus little of their biology is known. Two European species have been reared from Agelenidae, Clubionidae and Segestriidae spider egg sacs placed in concealed locations (Nielsen 1929). Porter (1979) observed the North American C. recurva (Say, 1835) running on tree trunks and possibly searching for concealed spider nests. In addition, he reported having seen one female of this species walking on a tree trunk, with a dead or paralysed spider adult still attached to the ovipositor. Gauld (1991) reported C. manni Cushman, 1921 reared as a possible idiobiont ectoparasitoid of an adult jumping spider (Salticidae) within its own egg sac. It is also known that at least some Neotropical Clistopyga species belong to mimicry complexes. Sääksjärvi et al. (2015) recently described a new species of Clistopyga from Peruvian Amazonia with a highly modified metasoma, C. caramba Castillo \& Sääksjärvi, 2015, and proposed two possible explanations for its bizarre morphology and colouration. According to one of the hypotheses, the modified metasoma of $C$. caramba resembles an ant and could be mimetic.

Gauld (1991) placed the Costa Rican species into two species groups: 1) the calixtoi group including all "typical" Clistopyga species with an apically upcurved and finely shagreened or coriaceous ovipositor, and 2) the henryi group including C. henryi Gauld, 1991 and some undescribed Neotropical and Afrotropical species with a long, straight and polished ovipositor. Based on a large number of Clistopyga specimens deposited in collections containing Neotropical ichneumonids and from our own long-term fieldwork in Colombia, Mexico and Peru, we have found dozens of new species and decided to place them into various species groups. These will be revised one by one in the near future.

We will start this work with the C. chaconi species group, which, in our opinion, is one of the most distinctive assemblages within the genus. Gauld (1991) placed C. chaconi Gauld, 1991 into his calixtoi species group. However, he did point out that this group would eventually have to be subdivided into more natural species groups.

We have found several new species from Mexico and South America, all closely related to C. chaconi. They all share a strong occipital carina, which is raised into a flange-like protuberance (Figs $2 \mathrm{~A}-\mathrm{B}$, 4A-B, 8A-B, 11E-F), as in most species of Acrotaphus Townes, 1960, Hymenoepimecis Viereck, 1912 and Ticapimpla Gauld, 1991. This species group seems to be endemic to the New World and currently includes only two described Neotropical species, C. chaconi and C. caramba.

The aim of this study is to revise the species of the $C$. chaconi species group and describe eleven new species collected from Argentina, Brazil, Colombia, Ecuador, Mexico, Paraguay and Peru. In addition, we provide a key and layer-photos for all species of the group. The current study is part of a larger project aiming to revise the New World Clistopyga started by Bordera et al. (2014) and Sääksjärvi et al. (2015).

\section{Material and methods}

Material of C. chaconi species group from the following institutions has been studied: 
AEIC = American Entomological Institute (Gainesville, Florida, USA)

$\mathrm{BMNH}=$ The Natural History Museum (London, UK)

CEUA $=$ Entomological Collection of the University of Alicante (Alicante, Spain)

FSCA = Florida State Collection of Arthropods (Department of Agriculture, Gainesville, Florida, USA)

IAVH = Instituto Alexander von Humboldt (Villa de Leyva, Boyacá, Colombia)

INBio = Instituto Nacional de Biodiversidad (Santo Domingo de Heredia, Costa Rica)

INPA = Instituto Nacional de Pesquisas da Amazônia (Petrópolis, Manaus, Brazil)

UNSM $=$ The Natural History Museum, University of San Marcos (Lima, Peru)

ZMUT $=$ Zoological Museum of the University of Turku (Turku, Finland)

Morphological terminology mostly follows that of Gauld (1991). Terminology used for description of sculpture is based on Eady (1968). Descriptions and measurements follow those of Bordera et al. (2014). Layer photos were taken in ZMUT using an Olympus SZX16 stereo microscope attached to an Olympus E520 digital camera. Digital photographs were combined using Deep Focus 3.1 and QuickPhoto Camera 2.3 programmes. Photos of C. mocaguae sp. nov. were taken in the Instituto Colombiano Agropecuario using a LEICA MC170 HD camera attached to a LEICA S8APO stereo microscope.

\section{Results}

\section{Diagnosis of the C. chaconi species group}

Gena in anterior view slightly rounded or almost straight and moderately to strongly constricted below eyes. Occipital carina complete, weakly to strongly raised, forming a dorsomedial flange (for a comparison with a typical Clistopyga head shape, see Bordera et al. 2014). Occiput in dorsal view straight. Malar space 0.5-1.1 times as long as basal mandibular width. Antenna with 30-36 flagellomeres, first flagellomere 4.6-7.0 times as long as wide. Epomia absent. Posterior part of median lobe of mesoscutum not prominent. Metapleuron 1.6-2.1 times as long as deep. Propodeum without lateromedian longitudinal carina, $0.9-1.2$ times as long as medially wide in dorsal view. Submetapleural carina complete, strongly raised and extending back to insertion of hind coxa. Hind leg with femur 3.4-4.2 times as long as deep and $0.8-1.0$ times as long as tibia. Sternite I of metasoma extending back $0.5-0.7$ of length of tergite. Ovipositor stout or slender, upcurved at apical 0.3-0.5, not denticulate in basal 0.35, matt, 1.1-1.6 times as long as hind tibia. Ovipositor sheath $0.9-1.3$ times as long as hind tibia, without denticles at basal ventral margin. Female fore leg with tibia unspecialized. Male gena without longitudinal concavity in ventral part.

\section{Key to the species of the $C$. chaconi species group}

1. Females (Figs 1A-C, 3A-D, 7A-E). Female of $C$. orellanae sp. nov. is unknown .................2

- Males (Fig. 10A-D). Males of C. caramba, C. melanoptera sp. nov. , C. cinnamoptera sp. nov., C. porteri sp. nov., C. misionensis sp. nov., C. rondoniae sp. nov., C. hayesiana sp. nov., C. cuscoensis sp. nov. and C. amazonica sp. nov. are unknown

2. Metasoma highly specialised, with segments V-VII strongly modified (Fig. 1A)

C. caramba Castillo \& Sääksjärvi, 2015

- Metasoma non-specialised .3

3. Wings strongly or moderately infuscate except in a broad hyaline band bordering veins $R s+2 r$,

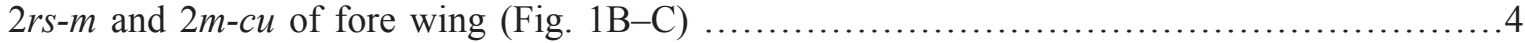

- Wings from hyaline to infuscate, but always without a hyaline band bordering veins $R s+2 r, 2 r s-m$ and $2 m-c u$ of fore wing (Figs 3A-D, 7A-E) 
4. Ovipositor slender, strongly upcurved at distal 0.45, about 1.4 times as long as hind tibia (Figs 1C, 2E). First flagellomere about 6.0 times as long as wide. Setae of ovipositor sheath, on average, about 1.35 times the sheath basal width (Fig. 2E). Tergite I twice as long as broad (Fig. 2C). Occipital carina strongly raised, forming a dorsomedial flange, conspicuously upcurved posteriorly (Fig. 2A). Malar space 0.8 times as long as basal mandibular width

C. melanoptera Castillo, Sääksjärvi \& Bordera sp. nov.

- Ovipositor stout, weakly upcurved in apical 0.5 , about 1.25 times as long as hind tibia (Figs 1B, 2F). First flagellomere about 4.8 times as long as wide. Setae of ovipositor sheath, on average, about 1.8 times the sheath basal width (Fig. 2F). Tergite I 2.3 times as long as broad (Fig. 2D). Occipital carina weakly raised, forming a flat flange dorsomedially (Fig. 2B). Malar space 1.0 times as long as basal mandibular width ................... cinnamoptera Bordera \& Sääksjärvi sp. nov.

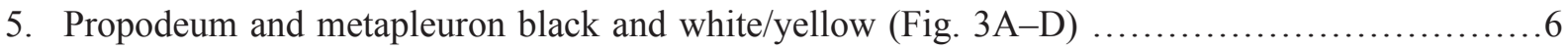

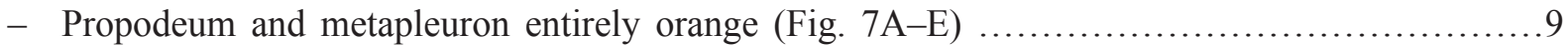

6. Clypeal suture slightly curved (Fig. 4C-D). Tergite II 1.0-1.2 times as long as broad (Fig. 5A-B). Metapleuron 1.5-1.7 times as long as deep. Antenna with 31-33 flagellomeres .....................

- Clypeal suture strongly curved (Fig. 6A-B). Tergite II 1.3-1.4 times as long as broad. Metapleuron 1.8-2.0 times as long as deep. Antenna with $35-36$ flagellomeres ............................ 8

7. Occipital carina weakly raised, forming a flat flange dorsomedially (Fig. 4A). Tergite II about 1.2 times as long as broad (Fig. 5A). Malar space 0.9-1.0 times basal width of mandible

C. chaconi Gauld, 1991

- Occipital carina strongly raised, forming a dorsomedial flange, conspicuously upcurved posteriorly (Fig. 4B). Tergite II as long as broad (Fig. 5B). Malar space about 0.65 times basal width of mandible

C. mocaguae Palacio \& Bordera sp. nov.

8. Mesopleuron ventrally and mesosternum yellow (Fig 3C). Hind wing with vein $c u-a+$ abscissa of $\mathrm{Cu} 1$ between $\mathrm{M}$ and $\mathrm{cu}-\mathrm{a}$ vertical (Fig. 6C). Epicnemial carina strong, reaching level of centre of pronotum. Gena, in frontal view, slightly rounded and strongly constricted below eyes (Fig. 6A). Ovipositor sinuous and slightly upcurved on apical 0.4 (Fig. 6E) ........... C. yabuquensis González-Moreno, Bordera \& Sääksjärvi sp. nov.

- Mesopleuron and mesosternum orange (Fig. 3D). Hind wing with vein $c u-a+$ abscissa of $\mathrm{Cu} 1$ between $M$ and $c u-a$ strongly reclivous (Fig. 6D). Epicnemial carina ending considerably below level of centre of pronotum. Gena, in frontal view, straight and moderately constricted below eyes (Fig. 6B). Ovipositor weakly and evenly upcurved on apical 0.5 (Fig. 6F) ...........

C. porteri Bordera \& Sääksjärvi sp. nov.

9. Hind coxa dorsally white, ventrally dark brown to black (Fig. 7A-B). Ovipositor stout, strongly upcurved over apical $0.3-0.4$ (Fig. 8E-F) ............................................ 10

- Hind coxa mostly tinged with orange (Fig. 7C-E). Ovipositor slender, weakly and evenly upcurved over apical $0.3-0.4$ (Fig. 9B, D, F) .......................................... 11

10 Clypeal suture slightly curved (Fig. 8C). Occipital carina moderately raised, forming a flat dorsomedial flange, slightly upcurved posteriorly (Fig. 8A). Tergites IV-VI with the dark brown area extending laterally backward on the white posterior band (Fig. 7A). Epicnemial carina weak, its dorsal end considerably below level of centre of pronotum. Wings hyaline, with a slightly yellow tint (Fig 7A)

C. misionensis Bordera \& Sääksjärvi sp. nov.

- Clypeal suture strongly curved (Fig. 8D). Occipital carina strongly raised, forming a dorsomedial flange, conspicuously upcurved posteriorly (Fig. 8B). Tergites IV-VI with the dark brown area not 
extending laterally backward on the posterior white band (Fig. 7B). Epicnemial carina absent. Wings moderately infuscate (Fig 7B). C. rondoniae Bordera \& Sääksjärvi sp. nov.

11. Antenna with 30 flagellomeres, first flagellomere about 4.9 times as long as wide. Clypeus twice as wide as long (Fig. 9A). Hind wing with vein $\mathrm{cu}-a$ about 0.9 times abscissa of $\mathrm{Cu}$ between $M$ and $c u-a$. Hind coxa dorsally white cream, ventrally orange (Fig. 7C). Hind femur mostly yellow cream, with basal and subapical dark brown and orange marks, respectively (Fig. 7C). Ovipositor about 1.5 times as long as hind tibia (Fig. 7C) ............... C. hayesiana Bordera \& Sääksjärvi sp. nov.

- Antenna with 33-36 flagellomeres, first flagellomere 5.8-6.1 times as long as wide. Clypeus $1.52-1.75$ times as wide as long (Fig. 9C, E). Hind wing with vein $c u-a$ 0.35-0.40 times abscissa of $\mathrm{Cu} 1$ between $M$ and $c u-a$. Hind coxa orange, dark brown in ventral distal part (Fig. 7D-E). Hind femur dark brown, distally and centrally (non-defined band) white (Fig. 7D-E). Ovipositor 1.3-1.4 times as long as hind tibia (Fig. 7D-E)

12. Clypeal suture slightly curved, almost straight (Fig. 9C). Setae of ovipositor sheath, on average, about 1.2 times the sheath basal width (Fig. 9D). Antenna with 33-34 flagellomeres. Malar space 0.55-0.65 times basal width of mandible. Tergite I 2.13-2.22 times as long as posteriorly broad C. cuscoensis Bordera, Castillo \& Sääksjärvi sp. nov.

- Clypeal suture strongly curved (Fig. 9E). Setae of ovipositor sheath, on average, about 3.0 times the sheath basal width (Fig. 9F). Antenna with 35-36 flagellomeres. Malar space 0.75-0.83 times basal width of mandible. Tergite I 1.7-1.8 times as long as posteriorly broad

C. amazonica Bordera \& Sääksjärvi sp. nov.

13. Propodeum and metapleuron entirely orange (Fig. 10A). Tergite I orange and black (Fig. 10A). Face with very fine and sparse setiferous punctures (Fig. 11A). First flagellomere about 6.7 times as long as wide C. orellanae Bordera \& Sääksjärvi sp. nov.

- Propodeum, metapleuron and tergite I black and white/yellow (Fig. 10B-D). Face strongly and densely punctate (Fig. 11B-D). First flagellomere 4.8-5.6 times as long as wide ...14

14. Clypeal suture strongly curved (Fig. 11B). Hind femur about 4.2 times as long as deep

C. yabuquensis González-Moreno, Bordera \& Sääksjärvi sp. nov.

- Clypeal suture weakly curved (Fig. 11C-D). Hind femur about 3.7 times as long as deep ...........15

15. Occipital carina weakly raised, forming a flat flange dorsomedially (Fig. 11E). Malar space about $0.8-0.9$ as long as basal mandibular width C. chaconi Gauld, 1991

- Occipital carina strongly raised, forming a dorsomedial flange, conspicuously upcurved posteriorly (Fig. 11F). Malar space about 0.65 times long as basal mandibular width ..... 


\author{
Class Insecta Linnaeus, 1758 \\ Order Hymenoptera Linnaeus, 1758 \\ Suborder Apocrita Latreille, 1810 \\ Superfamily Ichneumonoidea Latreille, 1802 \\ Family Ichneumonidae Latreille, 1802 \\ Subfamily Pimplinae Wesmael, 1845 \\ Tribe Ephialtini Hellén, 1915 \\ Genus Clistopyga Gravenhorst, 1829 \\ Clistopyga chaconi species group
}

Clistopyga amazonica Bordera \& Sääksjärvi sp. nov.

urn:1sid:zoobank.org:act:B51E4DCA-BBC9-4ECE-B016-637106652B88

Figs 7E, 9E-F

\title{
Diagnosis
}

Clistopyga amazonica sp. nov. can be distinguished from all other species of the $C$. chaconi species group by the combination of the following characters: wings hyaline; propodeum and metapleuron entirely orange; hind coxa orange, dark brown in ventral distal part; hind femur dark brown to black, distally and centrally (non-defined band) white (Fig. 7E); ovipositor slender, weakly and evenly upcurved over apical 0.4 (Figs 7E, 9F), 1.3-1.4 times as long as hind tibia; antenna with 35-36 flagellomeres, first flagellomere 5.9-6.1 times as long as wide; clypeus 1.52-1.64 times as wide as long; hind wing with vein $c u-a$ about 0.4 times abscissa of $C u 1$ between $M$ and $c u$ - $a$; clypeal suture strongly curved (Fig. 9E); setae of ovipositor sheath, on average, about 3.0 times the sheath basal width (Fig. 9F); malar space $0.75-0.83$ times basal width of mandible; tergite I $1.7-1.8$ times as long as posteriorly broad.

\section{Etymology}

The name of the species refers to Amazonia, the largest rain forest of the world.

\section{Material examined}

\section{Holotype}

BRAZIL: ㅇ, Amazonas, Manaus, Reserva 1208, Fazenda Esteio, PDBFF, 02²2'34" S, 5952'39" W, Malaise trap, 23 Jul. 1985, coll. B. Klein (INPA).

\section{Paratypes}

BRAZIL: 1 , same locality and collector as holotype, Reserva 1112, Fazenda Esteio, PDBFF, Sep. 1985 (INPA); 1 +, same locality and collector, ZF-03 Km 23 Reserva 1113, 02²6'02" S, 5951'15" W, Malaise trap, 5 Sep. 1985 (RCO) (INPA); 1 , same locality and collector, Reserva 1208, Fazenda Esteio, PDBFF, 02²2'34" S, 5952'39" W, 2 Jan. 1985 (INPA); 1 q, same data, 9 Apr. 1985 (INPA); 1 ㅇ, same data, 30 Jul. 1985 (INPA); 1 ㅇ, same data, 5 Nov. 1985 (INPA); 1 + , same data, 3 Dec. 1985 (INPA); 1 ㅇ, same locality and collector, Reserva 1301, Fazenda Esteio, PDBFF, 02²3'03" S, 59 51'15" W, Malaise trap, 8 May 1985 (INPA); 1 ㅇ, same data, 29 May 1985 (INPA); 2 $q$, same data, 19 Jun. 1985 (INPA); 1 , , same data, 3 Jul. 1985 (INPA).

FRENCH GUYANA: 1 , , Roura, Chevaux Montane, Malaise trap, Jun. 2009, coll. S.E.A.G. (ZMUT).

\section{Description}

\section{Female}

MeAsurements. Body length 8.5-10 mm. Fore wing length 5.9-7 mm. 
HEAD. In dorsal view, strongly narrowed behind eyes. Gena smooth and shiny with sparse, moderately long setae ventrally, in dorsal view $0.35-0.37$ times as long as eye, in frontal view straight and moderately constricted below eyes (Fig. 9E). Frons smooth and shiny, with a very weak medial longitudinal depression. Vertex smooth and shiny, with very isolated setiferous punctures. Posterior ocellus separated from eye 0.73-0.80 times its maximum diameter. Distance between hind ocelli 0.65-0.90 times maximum diameter of posterior ocellus. Occipital carina strongly raised, forming a dorsomedial flange, conspicuously upcurved posteriorly. Face with fine and dense setiferous punctures, distance between punctures about diameter of punctures. Clypeal suture strongly curved. Clypeus 1.52-1.64 times as broad as medially long, weakly convex in dorsal half, flat in ventral half, with apical margin truncate. Malar space $0.75-0.83$ times as long as basal mandibular width, with deep and narrow sulcus between eye and mandible, sulcus short, evanescent towards mandibular basis, forming a triangular granulate area (Fig. 9E). Antenna with 35-36 flagellomeres, first flagellomere 5.9-6.1 times as long as wide.

Mesosoma. Pronotum shiny, mostly smooth, with fine and sparse setiferous punctures in upper posterior part. Mesoscutum entirely smooth and shiny, median lobe anteriorly with very fine, shallow and sparse setiferous punctures. Notauli moderately deep, reaching about 0.6 of length of mesoscutum. Mesopleuron shiny, with moderately sparse and deep setiferous punctures, except in dorsal posterior part. Epicnemial carina weak, its dorsal end weakly curved backward, ending moderately far from anterior margin of mesopleuron at level of centre of pronotum. Metapleuron shiny, with fine and sparse setiferous punctures, 1.9-2.0 times as long as deep. Propodeum smooth and shiny, with sparse and fine setiferous punctures laterally; in dorsal view 1.0-1.1 times as long as medially wide. Propodeal spiracle contiguous, with groove separating propodeum and metapleuron, groove barely interrupted by spiracle. Hind leg with femur 3.8-3.85 times as long as deep, 0.90-0.95 times as long as tibia. Fore wing with vein $c u-a$ opposite $R s \& M$. Vein $2 r s-m$ about half length of abscissa of $M$ between $2 r s-m$ and $2 m-c u$. Abscissa of $C u 1$ between $1 m-c u$ and $C u 1$ a 1.5-1.7 times as long as $C u 1 b$. Hind wing with vein $c u-a$ about 0.4 times as long as abscissa of $C u 1$ between $M$ and $c u-a$. Vein $c u-a+$ abscissa of $C u 1$ between $M$ and $c u$ - $a$ slightly reclivous. Vein $C u 1$ very weakly pigmented.

Metasoma. Tergite I 1.7-1.8 times as long as posteriorly broad, smooth and shiny, with fine and relatively dense setiferous punctures laterally; spiracle near its basal 0.4 ; lateromedian longitudinal carinae strong, reaching about 0.3 of length of tergite; lateral longitudinal carinae strong, reaching about 0.2 of length of tergite. Sternite 1 extending back about 0.6 of length of tergite. Tergite II 1.20-1.26 times as long as posteriorly broad, central region shiny, with very fine and moderately sparse setiferous punctures; rest of tergites shiny, more densely and strongly punctate. Ovipositor slender, weakly and evenly upcurved at distal 0.4, somewhat matt, 1.3-1.4 times as long as hind tibia. Ovipositor sheath about 1.1 times as long as hind tibia, length of setae on average about 3.0 times the sheath basal width (Fig. 9F).

Colouration. Body primarily orange, black and white (Fig. 7E). Antenna brown, with scape, pedicel, and basal flagellomeres in ventral part pale. Head black with clypeus, base of mandible, ventral part of gena, inner eye orbit, two longitudinal blotches on the face and two transverse blotches under antennal sockets white. Palpi yellow. Mesosoma entirely orange except two sublateral black marks on posterior rim of propodeum. Tegula orange. Wings hyaline, pterostigma dark brown. Fore and mid legs orange. Hind leg black, with coxa anteriorly and dorsally marked with orange, femur distally and centrally (non defined band), wide band in the middle of tibia and proximal half of tarsal segments white. Metasoma dark brown to black, tergite I tinged with orange anteriorly, anterior corners of tergites II-IV and posterior band of tergites I-V (VIII) white, posterior corners of tergites I-III with black spots. Ovipositor brown. Ovipositor sheath black.

\section{Male}

Unknown. 


\section{Distribution}

Brazil, French Guyana.

Clistopyga caramba Castillo \& Sääksjärvi, 2015

Fig. 1A

\section{Diagnosis}

Clistopyga caramba is a very distinctive species and can be distinguished from all other species of the species group by the combination of the following characters: metasomal tergites I-IV white; tergites V-VI brown and extremely modified (resembling an ant in lateral view).

\section{Material examined}

\section{Holotype}

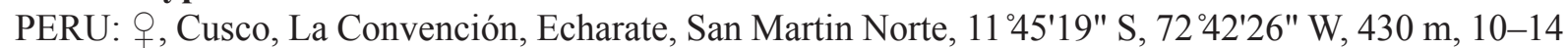
Nov. 2010, leg. B. Medina and Z. Bravo (UNSM).

\section{Remarks}

Additional characters to the original description are as follows: frons with a weak medial longitudinal groove; vertex smooth and shiny, with very isolated setiferous punctures; occipital carina weakly raised, forming a flat flange dorsomedially; face with fine and moderately sparse setiferous punctures, distance between punctures several times diameter of punctures; clypeal suture strongly curved; clypeus weakly convex in dorsal half, flat in ventral half; hind leg with femur about 4.0 times as long as deep; hind wing with vein $c u-a+$ abscissa of $C u 1$ between $M$ and $c u$ - $a$ vertical; ovipositor sheath with numerous oblique setae about same length or shorter than basal width of sheath.

\section{Distribution}

Peru.

Clistopyga chaconi Gauld, 1991

Figs 3A, 4A, C, 5A, C, 10C, 11C, E

\section{Diagnosis}

Clistopyga chaconi can be distinguished from all other species of the species group by the combination of the following characters: wings hyaline; propodeum and metapleuron black and white (Figs 3A, 10C); clypeal suture slightly curved (Figs 4C, 11C); antenna with 32 flagellomeres; occipital carina weakly raised, forming a flat flange dorsomedially (Figs 4A, 11E). Female with metapleuron 1.5 times as long as deep; tergite II about 1.2 times as long as broad (Fig. 5A) and malar space 0.9-1.1 times basal width of mandible. Male with face strongly and densely punctate (Fig. 11C); first flagellomere about 4.8 times as long as wide; hind femur about 3.7 times as long as deep and malar space about 0.75 as long as basal mandibular width.

\section{Material examined}

\section{Paratype}

COSTA RICA: 1 q, Guanacaste Prov., Guanacaste National Park, Cerro el Hacha, Casa oeste Tacotal, 400 m, Dec. 1986, coll. Gauld \& Janzen (BMNH).

\section{Remarks}

Additional characters to the original description are as follow: female with vertex smooth and shiny, with very isolated setiferous punctures; occipital carina strong, weakly raised, forming a flat flange 
dorsomedially (Fig. 4A); clypeal suture slightly curved (Fig. 4C); hind leg with femur 3.57-3.70 times as long as deep; hind wing with vein $c u-a+$ abscissa of $C u 1$ between $M$ and $c u-a$ vertical; tergite I with lateral longitudinal carina absent; ovipositor sheath with length of setae on average 2.4-3.0 times the sheath basal width (Fig. 5C). Male similar to female, but posterior ocellus separated from eye about 0.9 times its maximum diameter; distance between hind ocelli about 0.9 times maximum diameter of posterior ocellus; clypeus about 1.8 times as broad as medially long, quite strongly convex; malar space with deep and narrow sulcus between eye and mandible, about 0.8 times as long as basal mandibular
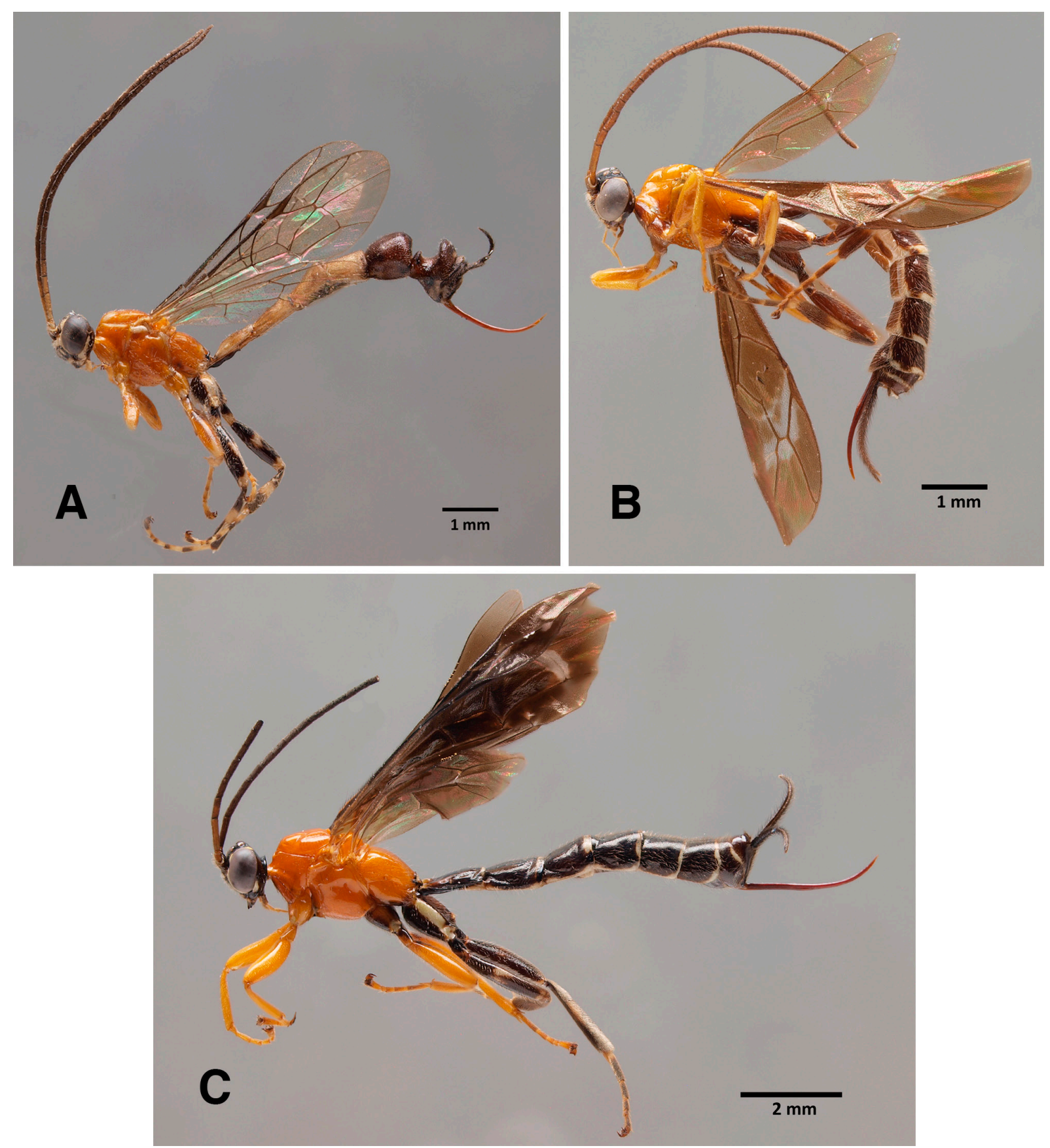

Fig. 1. Habitus of Clistopyga spp. 우. A. C. caramba Castillo \& Sääksjärvi, 2015, holotype. B. C. cinnamoptera Bordera \& Sääksjärvi sp. nov., holotype. C. C. melanoptera Castillo, Sääksjärvi \& Bordera sp. nov., holotype. 
width; lower part of gena, under eye, somewhat swollen (Fig. 11C); first flagellomere about 4.8 times as long as wide; epicnemial carina ending far from anterior margin of mesopleuron at level of centre of pronotum; metapleuron about 1.6 times as long as deep; propodeum in dorsal view about 0.95 times as long as medially wide; vein $2 r s-m$ longer than half length of abscissa of $M$ between $2 r s-m$ and $2 m$ $\mathrm{cu}$; tergite I about 1.85 times as long as posteriorly broad; spiracle near its basal 0.35 ; lateromedian longitudinal carina reaching about 0.5 of length of tergite, lateral longitudinal carinae strong, reaching about 0.3 of length of tergite; sternite I extending back about 0.5 of length of tergite; tergite II about 1.45 times as long as posteriorly broad.

\section{Distribution}

Costa Rica. The male from Yucatan (Mexico), reported by Bordera et al. (2014) as C. chaconi, is a paratype of C. yabuquensis sp. nov.

Clistopyga cinnamoptera Bordera \& Sääksjärvi sp. nov. urn:1sid:zoobank.org:act:63ED9485-E6D3-40D0-B907-58F1EFEA133D

Figs 1B, 2B, D, F

\section{Diagnosis}

Clistopyga cinnamoptera sp. nov. can be distinguished from all other species of the $C$. chaconi species group by the combination of the following characters: wings moderately infuscate, except in a broad hyaline band bordering veins $R s+2 r, 2 r s-m$ and $2 m-c u$ of fore wing (Fig. 1B); ovipositor stout, weakly upcurved in apical 0.5 (Fig. 2F), about 1.25 times as long as hind tibia; first flagellomere about 4.8 times as long as wide; setae of ovipositor sheath, on average, about 1.8 times the sheath basal width (Fig. 2F); tergite I 2.3 times as long as broad (Fig. 2D); occipital carina weakly raised, forming a flat flange dorsomedially (Fig. 2B); malar space 1.0 times as long as basal mandibular width.

\section{Etymology}

The name of the species refers to the infuscate wings.

\section{Material examined}

\section{Holotype}

ARGENTINA: ㅇ, Corrientes, CA. Corrientes, 8-20 Sep. 1969, coll. C. Porter (FSCA).

\section{Description}

\section{Female}

MEASUREMENTs. Body length $7 \mathrm{~mm}$. Fore wing length $6 \mathrm{~mm}$

HEAD. In dorsal view, strongly narrowed behind eyes. Gena smooth and shiny, with very sparse, moderately long setae ventrally, in dorsal view 0.35 times as long as eye, in frontal view slightly rounded and moderately constricted below eyes. Frons smooth and shiny, with a weak medial longitudinal depression. Vertex smooth and shiny, with very isolated setiferous punctures. Posterior ocellus separated from eye by about 1.1 times its maximum diameter. Distance between hind ocelli about 1.0 times maximum diameter of posterior ocellus. Occipital carina weakly raised, forming a flat flange dorsomedially (Fig. 2B). Face with shallow and dense setiferous punctures, distance between punctures less than twice diameter of punctures. Clypeal suture slightly curved. Clypeus about 1.6 times as broad as medially long, weakly convex in dorsal half, slightly concave in ventral half, with apical margin truncate. Malar space 1.0 times as long as basal mandibular width, with deep and narrow, smooth and shiny sulcus between eye and mandible. Antenna with 31 flagellomeres, first flagellomere about 4.8 times as long as wide. 
Mesosoma. Pronotum shiny, mostly smooth, with fine and sparse setiferous punctures in upper posterior part. Mesoscutum entirely smooth and shiny, median lobe anteriorly with very fine, shallow and sparse setiferous punctures. Notauli weak, reaching about 0.4 of length of mesoscutum. Mesopleuron shiny, mostly smooth, with very sparse and fine setiferous punctures, except in dorsal posterior part. Epicnemial carina very weak, its dorsal end terminating far from anterior margin of mesopleuron, considerably
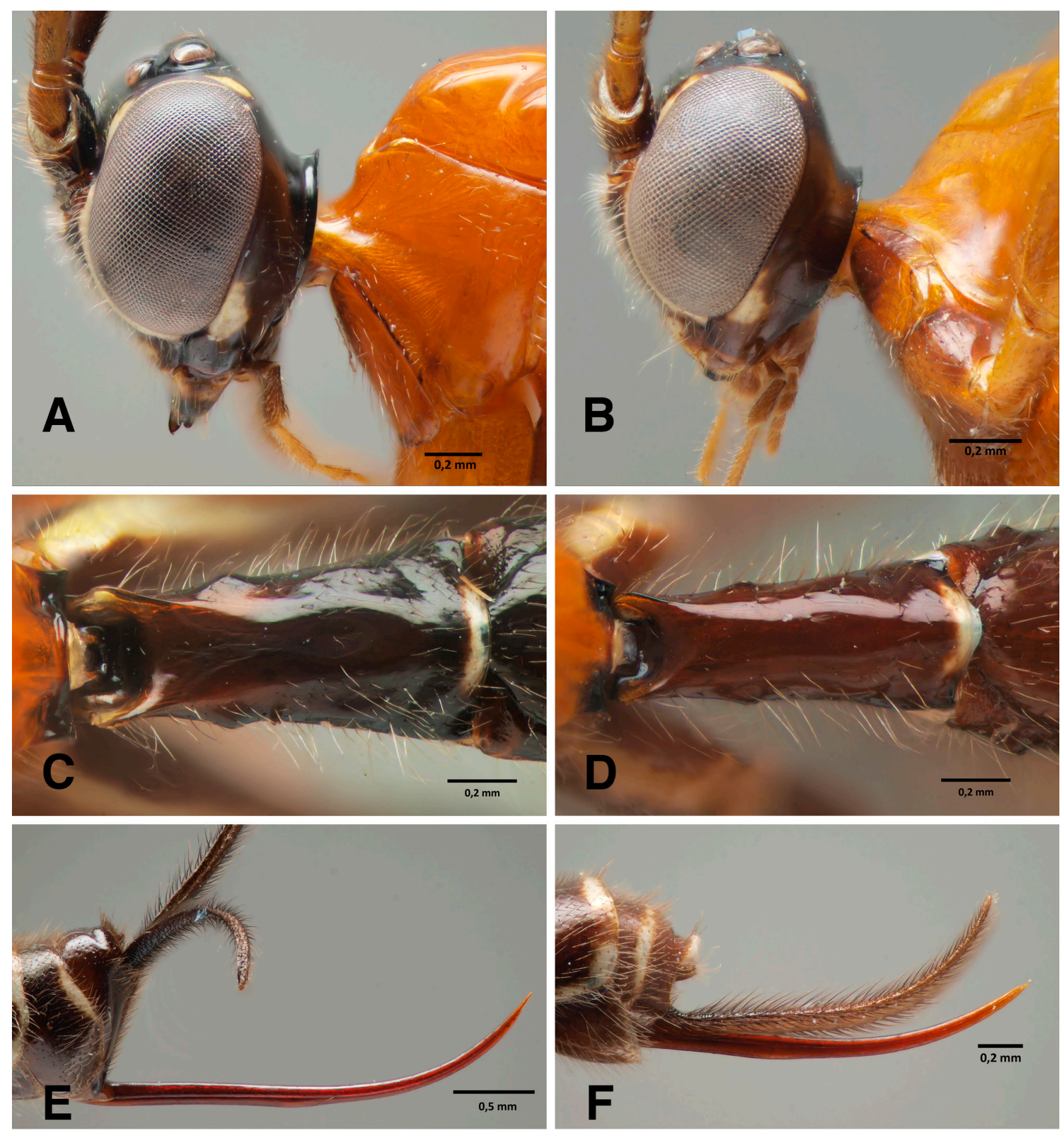

Fig. 2. Morphology of Clistopyga spp., $q$ + - - A-B. Head and pronotum, lateral view. A. C. melanoptera Castillo, Sääksjärvi \& Bordera sp. nov., holotype. B. C. cinnamoptera Bordera \& Sääksjärvi sp. nov., holotype. - C-D. Tergite I, dorsal view. C. C. melanoptera Castillo, Sääksjärvi \& Bordera sp. nov., holotype. D. C. cinnamoptera Bordera \& Sääksjärvi sp. nov., holotype. - E-F. Ovipositor, lateral view. E. C. melanoptera Castillo, Sääksjärvi \& Bordera sp. nov., holotype. F. C. cinnamoptera Bordera \& Sääksjärvi sp. nov., holotype. 
below level of centre of pronotum. Metapleuron smooth and shiny, with fine and sparse setiferous punctures, about 1.9 times as long as deep. Propodeum smooth and shiny, with sparse and fine setiferous punctures laterally; in dorsal view about 1.15 times as long as medially wide. Propodeal spiracle situated immediately above groove separating propodeum and metapleuron. Hind leg with femur 3.85 times as long as deep, 0.90 times as long as tibia. Fore wing with vein $c u-a$ opossite $R s \& M$. Vein $2 r s-m$ longer than half length of abscissa of $M$ between $2 r s-m$ and $2 m-c u$. Abscissa of $C u 1$ between $1 m-c u$ and $C u 1 \mathrm{a}$ about 1.65 times as long as $C u 1 b$. Hind wing with vein $c u-a$ about 0.6 times as long as abscissa of $C u 1$ between $M$ and $c u-a$. Vein $c u-a+$ abscissa of $C u 1$ between $M$ and $c u-a$ strongly reclivous. Vein $C u 1$ distinctly pigmented.

Metasoma. Tergite I about 2.3 times as long as posteriorly broad, smooth and shiny, with very fine and sparse setiferous punctures laterally and posteriorly; spiracle near its basal 0.35 ; lateromedian longitudinal carinae strong, reaching about 0.1 of length of tergite (Fig. 2D); lateral longitudinal carina absent. Sternite I extending back about 0.6 of length of tergite. Tergite II 1.35 times as long as posteriorly broad, central region shiny, with shallow and moderately sparse puctures; rest of tergites shiny, more densely punctate. Ovipositor stout, weakly upcurved in apical 0.5, matt (Fig. 2F), 1.25 times as long as
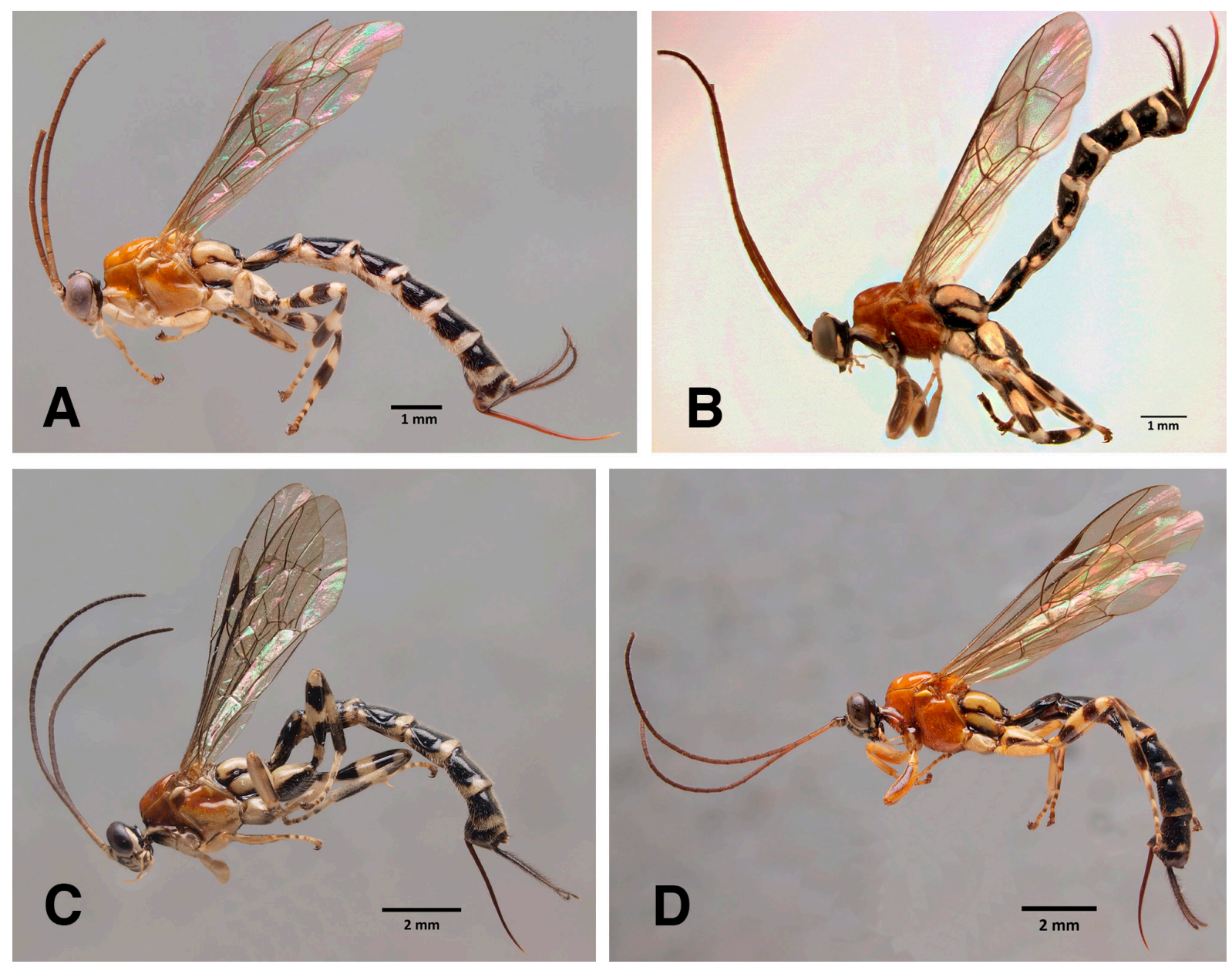

Fig. 3. Habitus of Clistopyga spp. 우. A. C. chaconi Gauld, 1991. B. C. mocaguae Palacio \& Bordera sp. nov., holotype. C. C. yabuquensis González-Moreno, Bordera \& Sääksjärvi sp. nov., holotype. D. C. porteri Bordera \& Sääksjärvi sp. nov., holotype. 
hind tibia. Ovipositor sheath about 1.0 times as long as hind tibia, length of setae on average about 1.8 times the sheath basal width (Fig. 2F).

Colouration. Body primarily orange, dark brown and white (Fig. 1B). Antenna light brown, pallid towards base of the external side including pedicel and apical part of scape. Head dark brown to black with upper part of clypeus, ventral part of gena, inner eye orbit (except an interruption at vertex), two longitudinal blotches on face and one transverse blotch under antennal sockets yellow. Palpi light orange. Mesosoma entirely orange except black dorsal hind border of propodeum, ventral part of metapleuron, propleuron, posterior part of mesosternum and metasternum strongly infuscate. Tegula light orange. Wings moderately infuscate, except in a broad hyaline band bordering veins $R s+2 r, 2 r s-m$ and $2 m-c u$ of fore wing. Fore leg mostly light brown, with coxa infuscate. Mid leg with coxa, trochanter, trochantellus and distal parts of tarsomeres dark brown, femur, tibia and basal part of tarsomeres light brown. Hind leg mostly dark brown, with dorsal part of coxa, apical band on femur, mid band of tibia and proximal parts of tarsi white. Metasoma dark brown, with posterior margins of tergites I-VII white, posterior corners
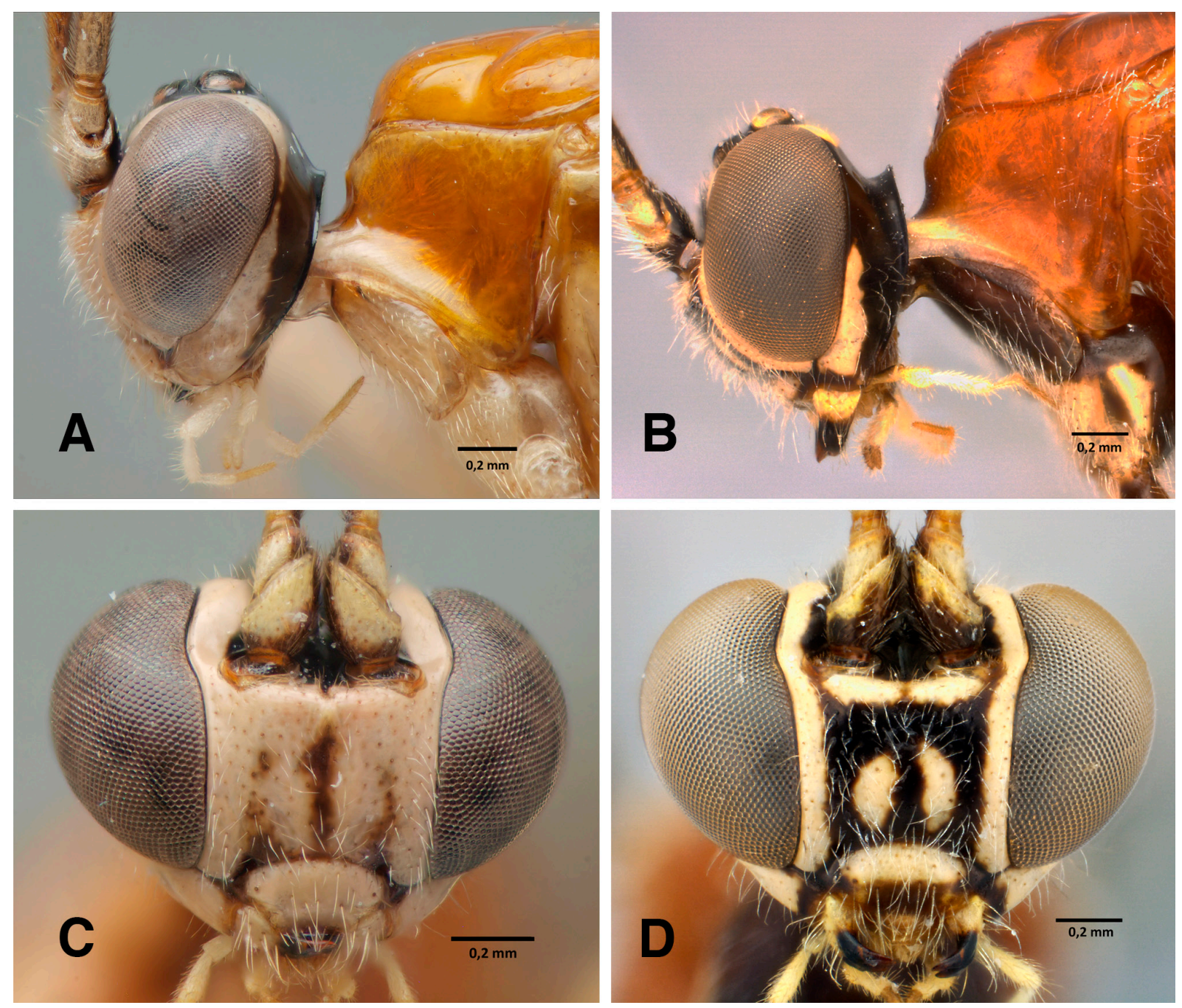

Fig. 4. Head and pronotum of Clistopyga spp., $q$ +.- A-B. Head and pronotum, lateral view. A. C. chaconi Gauld, 1991. B. C. mocaguae Palacio \& Bordera sp. nov., holotype. - C-D. Head, frontal view. C. C. chaconi Gauld, 1991. D. C. mocaguae Palacio \& Bordera sp. nov., holotype. 
of tergites II-III with black spots; tergites IV-VI with the dark brown area extending laterally backward. Ovipositor dark brown. Ovipositor sheath black.

\section{Male \\ Unknown. \\ Distribution}

Argentina.

Clistopyga cuscoensis Bordera, Castillo \& Sääksjärvi sp. nov. urn:1sid:zoobank.org:act:6B2FAB2E-9CB7-4A58-ADA2-C57A67DA6C96 Figs 7D, 9C-D

\section{Diagnosis}

Clistopyga cuscoensis sp. nov. can be distinguished from all other species of the $C$. chaconi species group by the combination of the following characters: wings hyaline; propodeum and metapleuron entirely orange; hind coxa orange, dark brown in ventral distal part; hind femur dark brown to black, distally and centrally (non-defined band) white (Fig. 7D); ovipositor slender, weakly and evenly upcurved over apical 0.3 (Figs 7D, 9D), 1.3-1.4 times as long as hind tibia; antenna with 33-34 flagellomeres, first flagellomere 5.8-6.0 times as long as wide; clypeus 1.65-1.75 times as wide as long (Fig. 9C); hind wing with vein $c u-a 0.35-0.40$ times abscissa of $C u 1$ between $M$ and $c u-a$; clypeal suture slightly curved, almost straight (Fig. 9C); setae of ovipositor sheath, on average, about 1.2 times the sheath basal width (Fig. 9D); malar space 0.55-0.65 times basal width of mandible; tergite I 2.13-2.22 times as long as posteriorly broad.

\section{Etymology}

The name of the species refers to the department where the holotype was collected, Cusco, Peru.
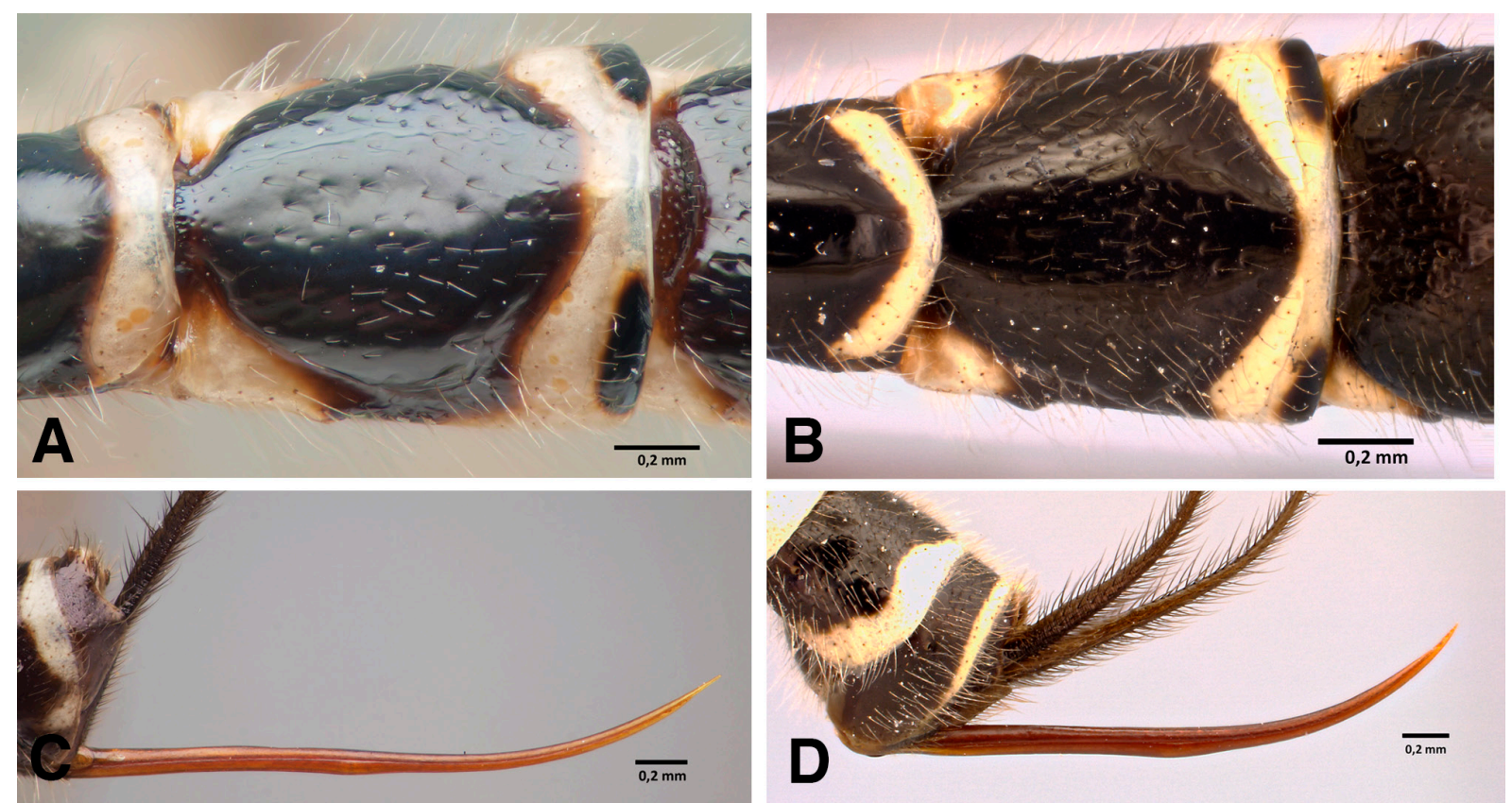

Fig. 5. Metasoma of Clistopyga spp., $\uparrow \odot .-$ A-B. Tergite II, dorsal view. A. C. chaconi Gauld, 1991. B. C. mocaguae Palacio \& Bordera sp. nov., holotype. - C-D. Ovipositor, lateral view. C. C. chaconi Gauld, 1991. D. C. mocaguae Palacio \& Bordera sp. nov., holotype. 


\section{Material examined}

\section{Holotype}

PERU: +, Dept. of Cusco, Cosñipata valley, checkpoint of PN Manu-Tono, 12 56'50" S, 71 $31^{\circ} 1^{\prime} 55^{\prime \prime} \mathrm{W}$, 865 m, Malaise trap, 13 Dec. 2007, coll. Castillo (UNSM).

\section{Paratypes}

PERU: 1 \%, near Marcapata, 15 Jan. 1962, coll. Luis Peña (AEIC).
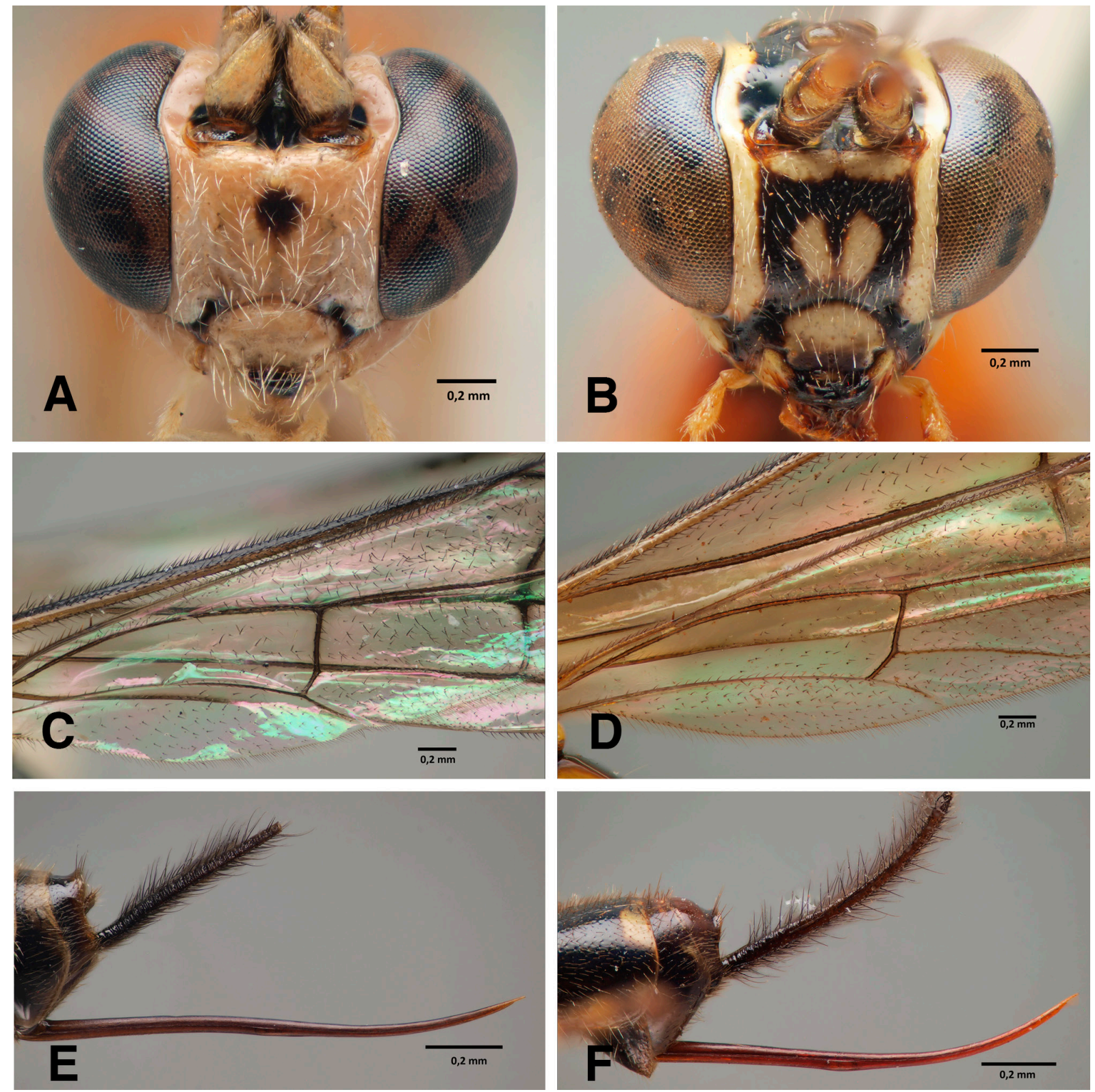

Fig. 6. Morphology of Clistopyga spp., 우. - A-B. Head, frontal view. A. C. yabuquensis GonzálezMoreno, Bordera \& Sääksjärvi sp. nov., paratype. B. C. porteri Bordera \& Sääksjärvi sp. nov., holotype. - C-D. Hind wing. C. C. yabuquensis González-Moreno, Bordera \& Sääksjärvi sp. nov., paratype. D. C. porteri Bordera \& Sääksjärvi sp. nov., holotype. - E-F. Ovipositor, lateral view. E. C. yabuquensis González-Moreno, Bordera \& Sääksjärvi sp. nov., paratype. F. C. porteri Bordera \& Sääksjärvi sp. nov., holotype. 

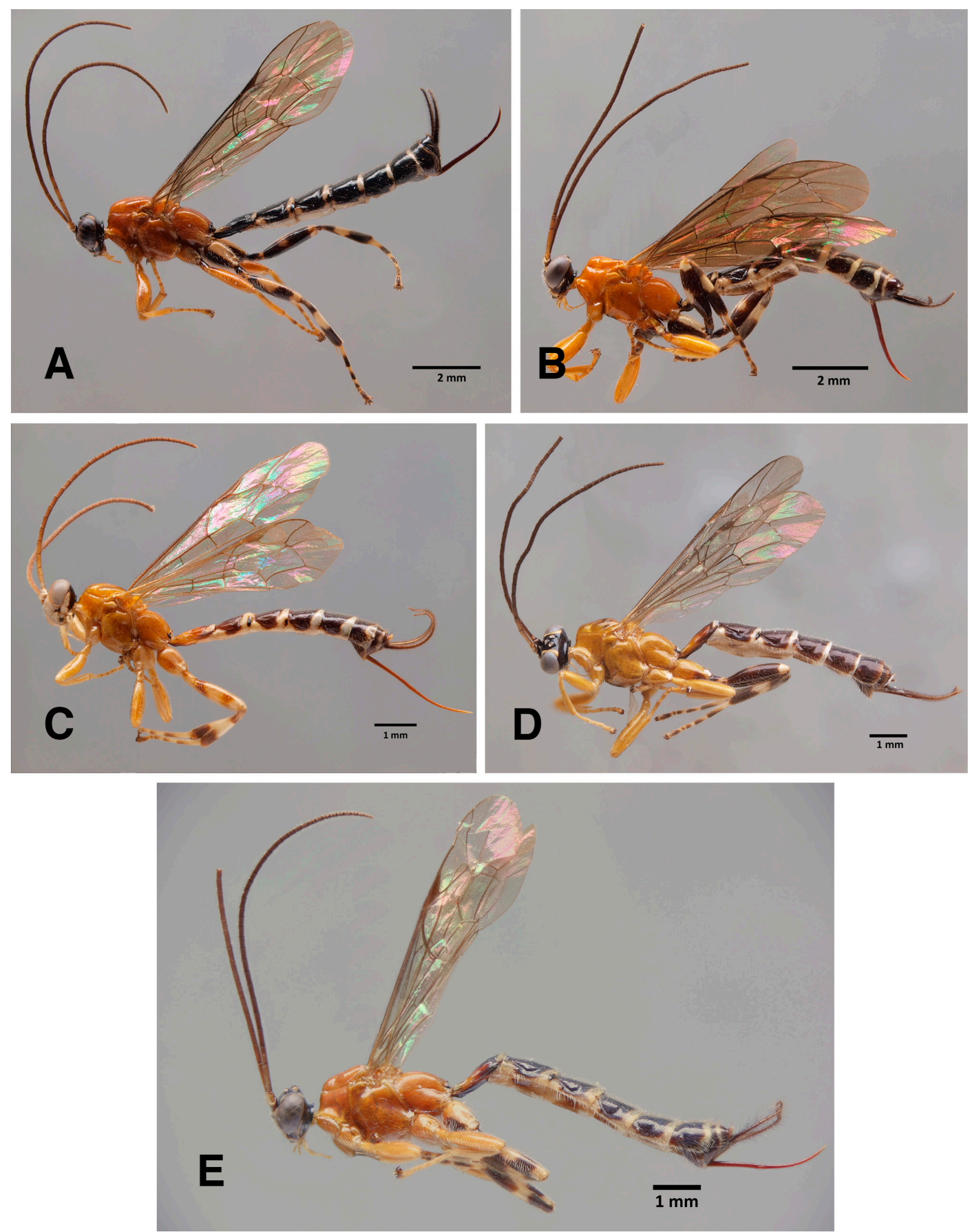

Fig. 7. Habitus of Clistopyga spp. 우. A. C. misionensis Bordera \& Sääksjärvi sp. nov., holotype. B. C. rondoniae Bordera \& Sääksjärvi sp. nov., holotype. C. C. hayesiana Bordera \& Sääksjärvi sp. nov., holotype. D. C. cuscoensis Bordera, Castillo \& Sääksjärvi sp. nov., paratype. E. C. amazonica Bordera \& Sääksjärvi sp. nov., holotype. 


\section{Description}

Female

MEASUREMENTS. Body length 9.4-10.3 mm. Fore wing length 6.5-6.9 mm

HEAD. In dorsal view, strongly narrowed behind eyes. Gena smooth and shiny, with sparse, moderately long setae ventrally, in dorsal view $0.35-0.38$ times as long as eye, in frontal view slightly rounded and moderately constricted below eyes (Fig. 9C). Frons smooth and shiny, with a very weak medial longitudinal depression. Vertex smooth and shiny, with very isolated setiferous punctures. Posterior ocellus separated from eye by $0.8-0.9$ times its maximum diameter. Distance between hind ocelli $0.8-0.9$ times maximum diameter of posterior ocellus. Occipital carina strongly raised, forming a dorsomedial flange, conspicuously upcurved posteriorly. Face with fine and dense setiferous punctures, distance between punctures about diameter of punctures (Fig. 9C). Clypeal suture slightly curved, almost straight. Clypeus 1.65-1.75 times as broad as medially long, weakly convex in dorsal half, flat in ventral half, with apical margin slightly rounded. Malar space $0.55-0.65$ times as long as basal mandibular width, with a deep, narrow, smooth and shiny sulcus between eye and mandible (Fig. 9C). Antenna with 33-34 flagellomeres, first flagellomere 5.8-6.0 times as long as wide.

Mesosoma. Pronotum shiny, mostly smooth, with fine and sparse setiferous punctures in upper posterior part. Mesoscutum entirely smooth and shiny, median lobe anteriorly with very fine, shallow and sparse setiferous punctures. Notauli shallow, reaching about 0.6 of length of mesoscutum. Mesopleuron shiny, mostly smooth, with very sparse and fine setiferous punctures except in dorsal part. Epicnemial carina moderately strong, its dorsal end far from anterior margin of mesopleuron, ending slightly below level of centre of pronotum. Metapleuron smooth and shiny, with fine and sparse setiferous punctures on the upper posterior part, 2.0-2.1 times as long as deep. Propodeum smooth and shiny, with sparse and fine setiferous punctures laterally, in dorsal view as long as medially wide. Propodeal spiracle situated immediately above groove separating propodeum and metapleuron. Hind leg with femur about 4.0 times as long as deep, 0.93-0.95 times as long as tibia. Fore wing with vein $c u-a$ opposite Rs\&M. Vein $2 r s-$ $m$ about half length of abscissa of $M$ between $2 r s-m$ and $2 m-c u$. Abscissa of $C u 1$ between $1 m-c u$ and $C u 1$ a 1.3-1.4 times as long as $C u 1$ b. Hind wing with vein $c u-a 0.35-0.40$ times as long as abscissa of $\mathrm{Cu} 1$ between $\mathrm{M}$ and $\mathrm{cu}-\mathrm{a}$. Vein $\mathrm{cu}-\mathrm{a}+$ abscissa of $\mathrm{Cu} 1$ between $\mathrm{M}$ and $\mathrm{cu}-a$ slightly reclivous. Vein $\mathrm{Cu} 1$ weakly pigmented.

Metasoma. Tergite I 2.13-2.22 times as long as posteriorly broad, smooth and shiny, with fine, sparse setiferous punctures laterally; spiracle near its basal 0.35; lateromedian longitudinal carinae strong, reaching about 0.2 of length of tergite; lateral longitudinal carinae absent. Sternite I extending back about 0.5 of length of tergite. Tergite II about 1.35 times as long as posteriorly broad, central region shiny, with very fine and moderately sparse setiferous punctures; rest of tergites shiny, more densely and strongly punctate. Ovipositor slender, weakly and evenly upcurved at distal 0.3, matt (Fig. 9D), 1.3-1.4 times as long as hind tibia. Ovipositor sheath about 1.1 times as long as hind tibia, length of setae on average about 1.2 times the sheath basal width (Fig. 9D).

Colouration. Body primarily orange, black and white (Fig. 7D). Antenna brown, with scape, pedicel and basal flagellomeres in ventral part pale. Head black with clypeus, base of mandible, ventral part of gena, inner eye orbit, two longitudinal blotches on the face and two transverse blotches under antennal sockets white. Palpi yellow. Mesosoma entirely orange, except two sublateral black marks on posterior rim of the propodeum. Tegula orange. Wings hyaline, pterostigma dark brown. Fore and mid legs orange. Hind leg black, with coxa anteriorly and dorsally marked with orange, femur distally and centrally (nondefined band), wide band in middle of tibia and proximal half of tarsal segments white. Metasoma dark brown, tergite I variably tinged with orange, anterior corners of tergites II-IV and posterior band of 
tergites I-IV (V) white, posterior corners of tergites I-III with black spots. Ovipositor brown. Ovipositor sheath black.

\author{
Male \\ Unknown. \\ Distribution
}

Peru.

Clistopyga hayesiana Bordera \& Sääksjärvi sp. nov. urn:lsid:zoobank.org:act:8D6472F1-31AA-404E-98D4-8C383E558AF0 Figs $7 \mathrm{C}, 9 \mathrm{~A}-\mathrm{B}$

\title{
Diagnosis
}

Clistopyga hayesiana sp. nov. can be distinguished from all other species of the $C$. chaconi species group by the combination of the following characters: wings hyaline with a slightly yellowish tint; propodeum and metapleuron entirely orange; hind coxa dorsally cream white, ventrally orange; hind femur mostly yellow cream, with basal and subapical dark brown and orange marks, respectively (Fig. 7C); ovipositor slender, sinuous, weakly and evenly upcurved over apical 0.3-0.4 (Figs 7C, 9B), about 1.55 times as long as hind tibia; antenna with 30 flagellomeres, first flagellomere about 4.9 times as long as wide; clypeus twice as wide as long (Fig. 9A); hind wing with vein $c u-a$ about 0.9 times abscissa of $C u 1$ between $M$ and $c u-a$.

\section{Etymology}

The name of the species refers to the area where the holotype was collected, Department of Presidente Hayes, Paraguay.

\section{Material examined}

\section{Holotype}

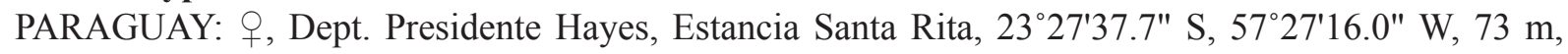
Malaise trap, 2-3 Oct. 2005, coll. B. Garcete (ZMUT).

\section{Description}

\section{Female}

Measurements. Body length $8 \mathrm{~mm}$. Fore wing length $6 \mathrm{~mm}$.

HEAD. In dorsal view, strongly narrowed behind eyes. Gena smooth and shiny, with very sparse, moderately long setae ventrally, in dorsal view 0.45 times as long as eye, in frontal view straight and moderately constricted below eyes (Fig. 9A). Frons smooth and shiny, with a very weak medial longitudinal depression. Vertex smooth and shiny, with very isolated setiferous punctures. Posterior ocellus separated from eye about 1.1 times its maximum diameter. Distance between hind ocelli about 1.0 times maximum diameter of posterior ocellus. Occipital carina moderately raised, forming a dorsomedial flange, weakly upcurved posteriorly. Face with fine and dense setiferous punctures, distance between punctures about diameter of punctures. Clypeal suture slightly curved, almost straight. Clypeus twice as broad as medially long, weakly convex in dorsal half, flat in ventral half, with apical margin truncate. Malar space 0.95 times as long as basal mandibular width, with deep and narrow sulcus between eye and mandible, sulcus short, evanescent towards mandibular base, forming a wide triangular granulate area (Fig. 9A). Antenna with 30 flagellomeres, first flagellomere about 4.9 times as long as wide. 
Mesosoma. Pronotum and mesoscutum entirely smooth and shiny. Notauli weak, reaching about 0.5 length of mesoscutum. Mesopleuron entirely smooth and shiny, with few fine setiferous punctures at lateral posterior part. Epicnemial carina very weak, its dorsal end ending far from anterior margin of
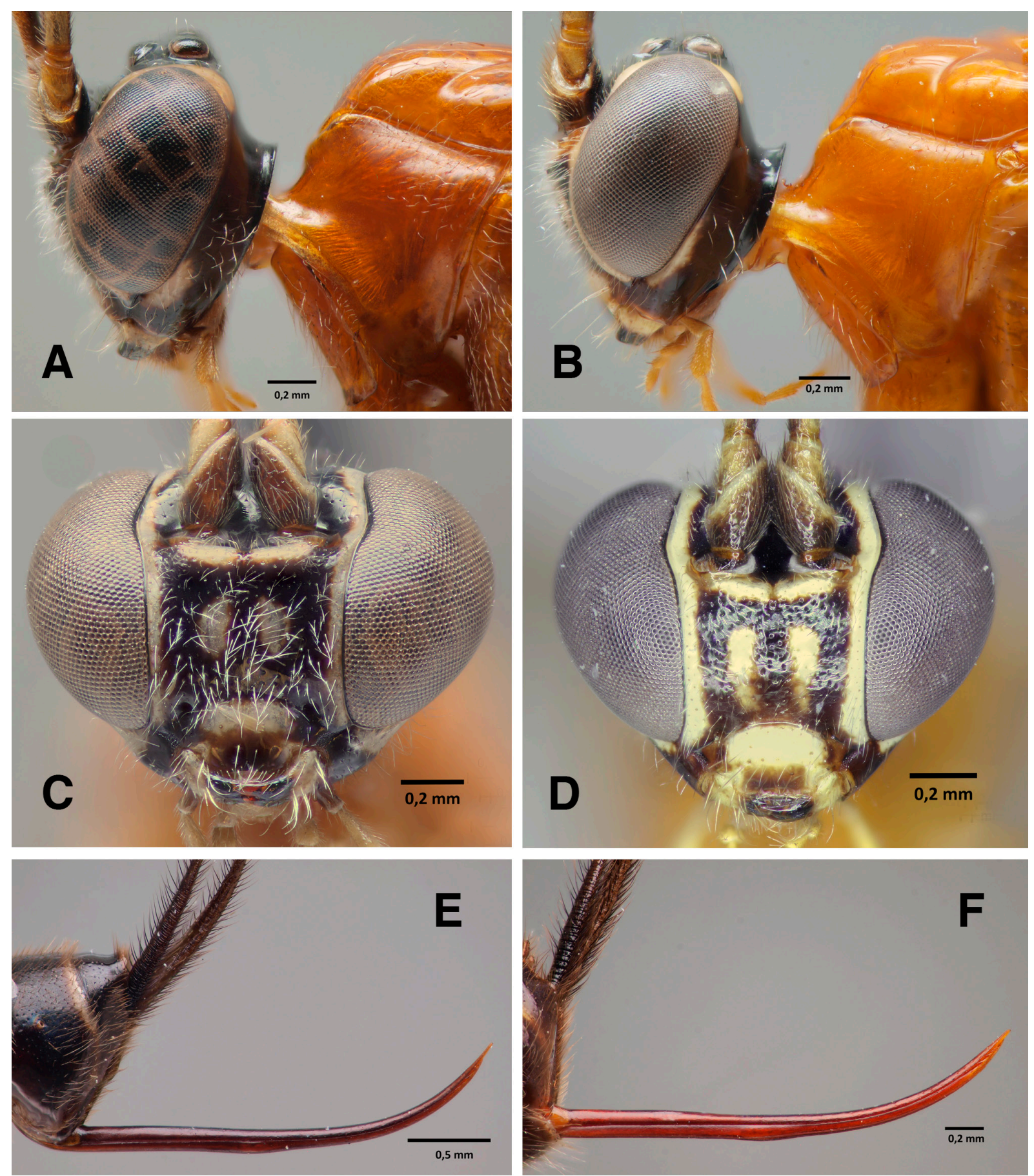

Fig. 8. Morphology of Clistopyga spp., $q+$. - A-B. Head and pronotum, lateral view. A. C. misionensis Bordera \& Sääksjärvi sp. nov., holotype. B. C. rondoniae Bordera \& Sääksjärvi sp. nov., holotype. C-D. Head, frontal view. C. C. misionensis Bordera \& Sääksjärvi sp. nov., holotype. D. C. rondoniae Bordera \& Sääksjärvi sp. nov., holotype. - E-F. Ovipositor, lateral view. E. C. misionensis Bordera \& Sääksjärvi sp. nov., holotype. F. C. rondoniae Bordera \& Sääksjärvi sp. nov., holotype. 
mesopleuron, considerably below level of centre of pronotum. Metapleuron smooth and shiny, with fine and very sparse setiferous punctures, about 1.9 times as long as deep. Propodeum smooth and shiny, with sparse and fine setiferous punctures laterally; in dorsal view about 1.0 times as long as medially wide. Propodeal spiracle situated immediately above groove separating propodeum and metapleuron. Hind leg with femur 3.7 times as long as deep, 0.8 times as long as tibia. Fore wing with vein $c u-a$ opposite $R s \& M$. Vein $2 r s-m$ about half length of abscissa of $M$ between $2 r s-m$ and $2 m-c u$. Abscissa of $\mathrm{Cu} 1$ between $1 \mathrm{~m}-\mathrm{cu}$ and $\mathrm{Cu} 1 \mathrm{a}$ about 1.8 times as long as $\mathrm{Cu}$ b. Hind wing with vein $c u-a 0.9$ times as long as abscissa of $C u 1$ between $M$ and $c u-a$. Vein $c u-a+$ abscissa of $C u 1$ between $M$ and $c u-a$ slightly reclivous. Vein $C u 1$ weakly pigmented.
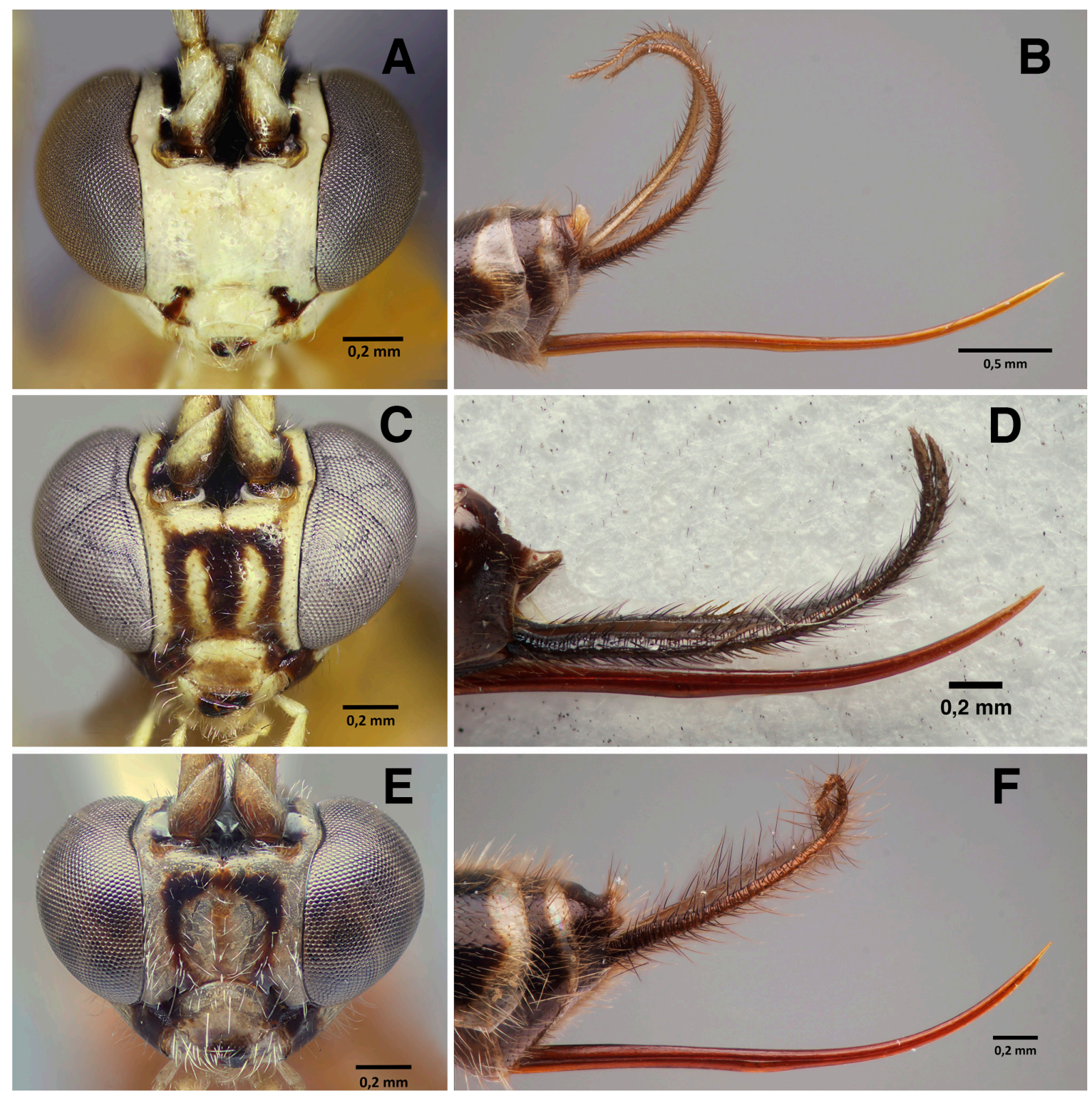

Fig. 9. Morphology of Clistopyga spp.,, $\uparrow .-$ A-B. C. hayesiana Bordera \& Sääksjärvi sp. nov., holotype. A. Head, frontal view. B. Ovipositor, lateral view. - C-D. C. cuscoensis Bordera, Castillo \& Sääksjärvi sp. nov. C. Head, frontal view, paratype. D. Ovipositor, lateral view, holotype. - E-F. C. amazonica Bordera \& Sääksjärvi sp. nov., paratype. E. Head, frontal view. F. Ovipositor, lateral view. 
Metasoma. Tergite I 1.75 times as long as posteriorly broad, smooth and shiny, with very fine, sparse setiferous punctures laterally and posteriorly; spiracle near its basal 0.35 ; lateromedian longitudinal carinae strong, reaching about 0.3 of length of tergite; lateral longitudinal carinae strong, reaching about 0.2 of length of tergite, sternite I extending back about 0.55 of length of tergite. Tergite II 1.25 times as long as posteriorly broad, central region shiny, with large, shallow and moderately sparse puctures; rest of tergites shiny, more denselly punctate. Ovipositor slender, sinuous, slightly upcurved over apical 0.35 , matt, about 1.55 times as long as hind tibia. Ovipositor sheath about 1.1 times as long as hind tibia, length of setae on average about twice sheath basal width (Fig. 9B).

Colouration. Body primarily orange, brown and white (Fig. 7C). Antenna light brown, yellowish towards base of external side including pedicel and apical part of scape. Head almost completely white, but frons, vertex, upper part of gena, teeth of mandible, clypeal foveae, malar sulcus and occiput black. Mesosoma entirely orange, except two sublateral black marks on posterior rim of propodeum. Tegula light brown. Wings hyaline with a slightly yellow tint, pterostigma blackish brown. Fore and mid legs yellow cream. Hind leg mostly yellow cream, ventral part of coxa, base of trochanter and subapical band on femur orange, base of femur, basal and distal part of tibia and apical parts of tarsi dark brown. Metasoma dark brown, tergite I mostly orange, yellowish at base, anterior corners of tergites II-IV white, posterior band of tergites I-VII white. Posterior corners of tergites II-III with black spots. Ovipositor light brown. Ovipositor sheath brown.

\section{Male \\ Unknown.}

\section{Distribution}

Paraguay.

Clistopyga melanoptera Castillo, Sääksjärvi \& Bordera sp. nov. urn:lsid:zoobank.org:act:AD1363FD-5A3D-41F1-A059-465007DB5AEC

Figs $1 \mathrm{C}, 2 \mathrm{~A}, \mathrm{C}, \mathrm{E}$

\section{Diagnosis}

Clistopyga melanoptera sp. nov. can be distinguished from all other species of the C. chaconi species group by the combination of the following characters: wings strongly infuscate, except in a broad hyaline band bordering veins $R s+2 r, 2 r s-m$ and $2 m-c u$ of fore wing (Fig. 1C); ovipositor slender, strongly upcurved at distal 0.45, about 1.4 times as long as hind tibia (Figs 1C, 2E); first flagellomere about 6.0 times as long as wide; setae of ovipositor sheath, on average, about 1.35 times the sheath basal width (Fig. 2E); tergite I twice as long as posteriorly broad (Fig. 2C); occipital carina strongly raised, forming a dorsomedial flange, conspicuously upcurved posteriorly (Fig. 2A); malar space 0.8 times as long as basal mandibular width.

\section{Etymology}

The name refers to the dark wings of the new species.

\section{Material examined}

\section{Holotype}

PERU: , Dept. of Cusco, Reserva comunal Amarakaeri, $12^{\circ} 55^{\prime} \mathrm{S}, 70^{\circ} 51^{\prime} \mathrm{W}, 333-884 \mathrm{~m}$, Malaise trap, 4 Nov. 2010, coll. M. Vilchez \& C. Castillo (UNSM). 


\section{Description}

Female

Measurements. Body length $11 \mathrm{~mm}$. Fore wing length $8 \mathrm{~mm}$.

HEAD. In dorsal view, strongly narrowed behind eyes. Gena smooth and shiny, with sparse, moderately long setae ventrally, in dorsal view about 0.4 times as long as eye, in frontal view straight and moderately constricted below eyes. Frons smooth and shiny, with a weak medial longitudinal depression. Vertex smooth and shiny, with very isolated setiferous punctures. Posterior ocellus separated from eye about 1.0 times its maximum diameter. Distance between hind ocelli about 0.9 times maximum diameter of posterior ocellus. Occipital carina strongly raised and forming a dorsomedial flange, conspicuously upcurved posteriorly (Fig. 2A). Face with fine and dense setiferous punctures, distance between punctures about diameter of punctures. Clypeal suture slightly curved. Clypeus 1.65 times as broad as medially long, weakly convex in dorsal half, flat in ventral half, with apical margin slightly rounded. Malar space 0.8 times as long as basal mandibular width, with deep and narrow granulate sulcus between eye and mandible. Antenna broken in unique holotype, with 14+ flagellomeres, first flagellomere about 6.0 times as long as wide.

Mesosoma. Pronotum shiny, mostly smooth, with fine and sparse setiferous punctures in upper posterior part. Mesoscutum entirely smooth and shiny, median lobe anteriorly with very fine shallow and sparse setiferous punctures. Notauli weak, reaching about 0.4 of length of mesoscutum. Mesopleuron shiny, mostly smooth, with very sparse and fine setiferous punctures except in dorsal posterior part. Epicnemial carina very weak, its dorsal end ending far from anterior margin of mesopleuron, considerably below level of centre of pronotum. Metapleuron smooth and shiny, with fine and sparse setiferous punctures, about 1.9 times as long as deep. Propodeum smooth and shiny, with sparse and fine setiferous punctures laterally; in dorsal view 1.16 times as long as medially wide. Propodeal spiracle situated immediately above groove separating propodeum and metapleuron. Hind leg with femur 3.85 times as long as deep, about 0.9 times as long as tibia. Fore wing with vein $c u-a$ opposite $R s \& M$. Vein $2 r s-m$ longer than half length of abscissa of $M$ between $2 r s-m$ and $2 m$-cu. Abscissa of $C u 1$ between $1 m-c u$ and $C u 1$ a about 2.35 times as long as $C u 1 \mathrm{~b}$. Hind wing with vein $c u-a 0.52$ times as long as abscissa of $C u 1$ between $M$ and $c u-a$. Vein $c u-a+$ abscissa of $C u 1$ between $M$ and $c u-a$ slightly reclivous. Vein $C u 1$ distinctly pigmented.

Metasoma. Tergite I about twice as long as posteriorly broad, smooth and shiny, with very fine, relatively dense setiferous punctures laterally and posteriorly; spiracle near its basal 0.4 ; lateromedian longitudinal carinae strong, reaching about 0.2 of length of tergite; lateral longitudinal carina absent (Fig. 2C). Sternite I extending back about 0.6 of length of tergite. Tergite II 1.35 times as long as posteriorly broad, central region shiny, with shallow and dense punctures, rest of tergites shiny, more densely punctate. Ovipositor slender, strongly upcurved at distal 0.45, matt, about 1.4 times as long as hind tibia (Figs 1C, 2E). Ovipositor sheath about 1.1 times as long as hind tibia, length of setae on average about 1.3 times sheath basal width (Fig. 2E).

Colouration. Body primarily orange, black and white (Fig. 1C). Antenna brownish, pallid towards base of external side including pedicel and distal rim of scape. Head black with upper part of clypeus, base of mandible, ventral part of gena, inner eye orbit (except an interruption at vertex), two longitudinal rectangular blotches on face and two transverse blotches under antennal sockets yellow. Palpi orange. Mesosoma entirely orange except dorsal posterior border of propodeum black. Tegula orange. Wings strongly infuscate except in a broad hyaline band bordering veins $R s+2 r, 2 r s-m$ and $2 m-c u$ of fore wing. Pterostigma dark brown. Fore legs orange, mid leg mostly orange, with ventral part of coxa, posterior part of trochanter and basal posterior part of femur dark brown to black. Hind leg black, with dorsal band on coxa, a not delineated mark on mid dorsal part of femur, a partial band in middle of tibia and proximal part of tarsomeres yellowish. Metasoma black, anterior part of tergite I yellow and orange, 
posterior band of tergites I-VII white. Posterior corners of tergites II-III with black spots. Ovipositor dark brown. Ovipositor sheath black.

\author{
Male \\ Unknown. \\ Distribution \\ Peru. \\ Clistopyga misionensis Bordera \& Sääksjärvi sp. nov. \\ urn:1sid:zoobank.org:act:3DDD2179-58C9-481E-801B-3307D20A0A0D
}

Figs $7 \mathrm{~A}, 8 \mathrm{~A}, \mathrm{C}, \mathrm{E}$

\title{
Diagnosis
}

Clistopyga misionensis sp. nov. can be distinguished from all other species of the C. chaconi species group by the combination of the following characters: wings hyaline with a slightly yellowish tint; propodeum and metapleuron entirely orange; hind coxa dorsally white, ventrally dark brown to black (Fig. 7A); ovipositor stout, strongly upcurved over apical 0.3-0.4 (Figs 7A, 8E); clypeal suture slightly curved (Fig. 8C); occipital carina moderately raised, forming a flat dorsomedial flange, slightly upcurved posteriorly (Fig. 8A); tergites IV-VI with the dark brown area extending laterally backward on the white posterior band (Fig. 7A); epicnemial carina weak, its dorsal end considerably below level of centre of pronotum.

\section{Etymology}

The name of the species refers to the area where the holotype was collected, Misiones province, Argentina.

\section{Material examined}

\section{Holotype}

ARGENTINA: + , Provincia Misiones, reg. Loreto, Ruinas Jesuiticias, $27^{\circ} 19^{\prime} \mathrm{S}, 55^{\circ} 32^{\prime} \mathrm{W}, 865 \mathrm{~m}$, Malaise trap, 8 Aug.-9 Sep. 2001 (ZMUT).

\section{Paratypes}

ARGENTINA: 1 , same data as holotype (ZMUT); 1 \&, 7 Jun. -9 Jul. 2001, coll. P. Fidalgo (ZMUT); 1 \&, same prov., in subtropical wet forest, 1-31 Jan. 2001 (FSCA); 1 ㅇ, same prov., Puerto Rico, Malaise trap, 5-13 Nov. 1970, coll. C. Porter \& L. Stange (FSCA); 1 +, Las Marías, ca. Gdor. Viresoro, Aug. 1971, coll. C. Porter (FSCA).

PERU: 1 †, 300 m, near Marcapata, 1-15 Oct. 1962, coll. Luis Peña (AEI).

\section{Description}

\section{Female}

MeAsurements. Body length 9-11 mm. Fore wing length 6-8 mm.

HEAD. In dorsal view, strongly narrowed behind eyes. Gena smooth and shiny, with sparse, moderately long setae ventrally, in dorsal view $0.31-0.38$ times as long as eye, in frontal view straight and moderately constricted below eyes (Fig. 8C). Frons smooth and shiny, with a very weak medial longitudinal depression. Vertex smooth and shiny, with very isolated setiferous punctures. Posterior ocellus separated from eye by 0.9-1.0 times its maximum diameter. Distance between hind ocelli 0.75-0.93 times maximum diameter of posterior ocellus. Occipital carina moderately raised, forming a flat dorsomedial 
flange, slightly upcurved posteriorly (Fig. 8A). Face with strong and dense setiferous punctures, distance between punctures about diameter of punctures. Clypeal suture slightly curved. Clypeus 1.52-1.74 times as broad as medially long, weakly convex in dorsal half, flat in ventral half, with apical margin truncate. Malar space $0.75-0.85$ times as long as basal mandibular width, with deep and narrow sulcus between eye and mandible, sulcus short, evanescent towards mandibular base, forming a triangular granulate area (Fig. 8C). Antenna with 33 flagellomeres, first flagellomere 5.56-7.0 times as long as wide.

Mesosoma. Pronotum shiny, mostly smooth, with very fine and sparse setiferous punctures in upper posterior part. Mesoscutum entirely smooth and shiny, median lobe anteriorly with very fine, shallow and sparse setiferous punctures. Notauli shallow, reaching about 0.5 of length of mesoscutum. Mesopleuron shiny, mostly smooth, with moderately sparse and fine setiferous punctures except in dorsal posterior part. Epicnemial carina weak, its dorsal end weakly curved backward, ending moderately far from anterior margin of mesopleuron, considerably below level of centre of pronotum. Metapleuron smooth and shiny, with fine and sparse setiferous punctures, 1.82-1.90 times as long as deep. Propodeum smooth and shiny, with sparse and fine setiferous punctures except in dorsal posterior part; in dorsal view 0.97 1.0 times as long as medially wide. Propodeal spiracle situated above groove separating propodeum and metapleuron. Hind leg with femur 3.7-3.8 times as long as deep, 0.92-1.0 times as long as tibia. Fore wing with vein $c u-a$ more or less opposite $R s \& M$. Vein $2 r s-m$ longer than half length of abscissa of $M$ between 2rs-m and 2m-cu. Abscissa of $C u 1$ between $1 m-c u$ and $C u 1$ a 1.53-2.0 times as long as $C u 1 b$. Hind wing with vein $c u-a 0.39-0.41$ times as long as abscissa of $C u 1$ between $M$ and $c u-a$. Vein $c u-a+$ abscissa of $C u 1$ between $M$ and $c u-a$ slightly reclivous. Vein $C u 1$ barely pigmented.

Metasoma. Tergite I 1.67-1.79 times as long as posteriorly broad, smooth and shiny, with very fine, relatively dense setiferous punctures laterally and posteriorly; spiracle near its basal 0.4 ; lateromedian longitudinal carinae strong, reaching about 0.2 of length of tergite; lateral longitudinal carinae strong, reaching about 0.35 of length of tergite. Sternite I extending back about 0.5 of length of tergite. Tergite II 1.04-1.15 times as long as posteriorly broad, central region shiny, with fine and moderately dense setiferous punctures; rest of tergites shiny, more densely punctate. Ovipositor stout, strongly upcurved at distal 0.35, matt (Fig. 8E), 1.3-1.43 times as long as hind tibia. Ovipositor sheath about 1.0-1.1 times as long as hind tibia; length of setae on average about 1.3 times sheath basal width (Fig. 8E).

Colouration. Body primarily orange, black and white (Fig 7A). Antenna brownish, pallid towards base of external side including pedicel and distal rim of scape. Head black with clypeus, base of mandible, ventral part of gena, inner eye orbit, two longitudinal blotches on the face and two transverse blotches under antennal sockets white. Palpi orange. Mesosoma entirely orange, except two sublateral black marks on posterior rim of propodeum, sometimes posterior part of metapleuron and sublateral posterior part of propodeum yellowish. Tegula orange. Wings hyaline, with a slightly yellow tint, pterostigma brown. Fore leg orange. Mid leg mostly orange, with coxa dorsally and proximal part of tarsomeres yellowish, ventral part of coxa entirely or partially, posterior part of trochanter and distal part of tarsomeres dark brown. Hind leg black with coxa dorsally, trochanter apically and sometimes trochantellus, femur distally and centrally (non-defined band), wide band in middle of tibia and proximal half of tarsal segments white. Metasoma dark brown to black, anterior corners of tergites I-IV and posterior band of tergites IVI (VII) white, posterior corners of tergites I-III with black spots, tergites IV-VI with dark brown area extending laterally backward. Ovipositor dark brown. Ovipositor sheath black.

\section{Male \\ Unknown.}

\section{Distribution}

Argentina, Peru. 
Clistopyga mocaguae Palacio \& Bordera sp. nov. urn:1sid:zoobank.org:act:D7BB97D8-34D9-4F33-907C-2BA760A5E16B

Figs 3B, 4B, D, 5B, D, 10D, 11D, F

\section{Diagnosis}

Clistopyga mocaguae sp. nov. can be distinguished from all other species of the C. chaconi species group by the combination of the following characters: wings hyaline, propodeum and metapleuron black and white or cream yellow (Figs 3B, 10D); clypeal suture slightly curved (Figs 4D, 11D); antenna with about 33 flagellomeres; occipital carina strongly raised, forming a dorsomedial flange, conspicuously upcurved posteriorly (Figs 4B, 11F) and malar space about 0.65 times basal width of mandible. Female with tergite II as long as broad (Fig. 5B); metapleuron 1.7 times as long as deep. Male with face strongly and densely punctate (Fig. 11D), first flagellomere 5.6 times as long as wide and hind femur about 3.7 times as long as deep.

\section{Etymology}

The name of the species refers to the locality where the type was collected, Mocagua, Amazonas.

\section{Material examined}

\section{Holotype}

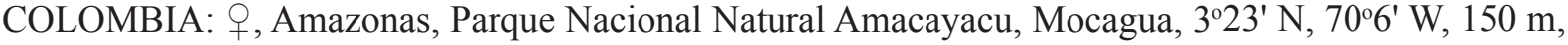
Malaise trap, 14-21 Aug. 2000, coll. A. Parente (IAVH).

\section{Paratype}

COLOMBIA: 1 §, same locality and collector, Malaise trap, 7-14 Aug. 2000 (IAVH).

\section{Description}

\section{Female}

Measurements. Body length $10.2 \mathrm{~mm}$. Fore wing length $7 \mathrm{~mm}$.

HEAD. In dorsal view, strongly narrowed behind eyes. Gena with very few isolated, fine setiferous punctures, in dorsal view 0.4 times as long as eye, in anterior view slightly rounded and strongly constricted below eyes (Fig. 4D). Frons smooth and shiny. Vertex smooth and shiny, with very isolated setiferous punctures. Posterior ocellus separated from eye by 0.95 times its maximum diameter. Distance between hind ocelli 0.9 times maximum diameter of posterior ocellus. Occipital carina strongly raised, forming a dorsomedial flange, conspicuously upcurved posteriorly (Fig. 4B). Occiput in dorsal view straight. Face strongly and densely punctate, distance between punctures less than twice diameter of puncture. Clypeal suture slightly curved. Clypeus 1.85 times as broad as medially long, quite strongly convex. Malar space with deep and narrow sulcus between eye and mandible, 0.65 times as long as basal mandibular width (Fig. 4D). Antenna with at least 30 flagellomeres (distal flagellomeres missing in single available female), first flagellomere about 5.6 times as long as wide.

Mesosoma. Pronotum mostly smooth and shiny, finely punctate in upper part. Epomia absent. Mesoscutum smooth and shiny, with very sparse setiferous punctures on median and lateral lobes. Notauli shallow, extending from anterolateral margin of mesoscutum to about 0.4 its length. Mesopleuron shiny, mostly smooth, with moderately strong and sparse setiferous punctures except in dorsal posterior part; ventrally slightly granulate. Epicnemial carina strong, with dorsal end almost straight, ending far from anterior margin of mesopleuron below level of centre of pronotum. Metapleuron smooth and shiny, sometimes with sparse fine setiferous punctures dorsally, 1.7 times as long as deep. Propodeum smooth and shiny, with very sparse and fine setiferous punctures laterally; in dorsal view 1.0 times as long as medially 
wide. Propodeal spiracle situated immediately above groove separating propodeum and metapleuron. Hind leg with femur about 3.4 times as long as deep, 0.9 as long as tibia. Fore wing with vein $c u-a$ opposite $R s \& M$. Vein $2 r s-m$ slightly longer than half length of abscissa of M between $2 r s-m$ and $2 m-c u$. Abscissa of $C u 1$ between $1 m-c u$ and $C u 1$ a about 1.8 times as long as $C u 1 b$. Hind wing with vein $c u-a$ 0.45 times as long as abscissa of $C u 1$ between $M$ and $c u-a$. Vein $c u-a+$ abscissa of $C u 1$ between $M$ and $c u-a$ vertical. Vein $C u 1$ distinctly pigmented.

Metasoma. First tergite 1.75 times as long as posteriorly broad, smooth and shiny, with very fine, sparse setiferous punctures laterally and posteriorly; spiracle near its basal 0.35 ; lateromedian longitudinal carina strong, reaching about 0.3 of length of tergite, lateral longitudinal carina absent. Sternite I extending back about 0.6 of length of tergite. Second tergite 1.0 times as long as posteriorly broad, central region with large, shallow, sparse setiferous punctures (Fig. 5B); rest of tergites shiny, more densely and strongly punctate. Ovipositor slender, distinctly upcurved at distal $0.45,1.4$ times as long as hind tibia. Ovipositor sheath 1.4 times as long as hind tibia, length of setae on average about 2.4 times sheath basal width (Fig. 5D).
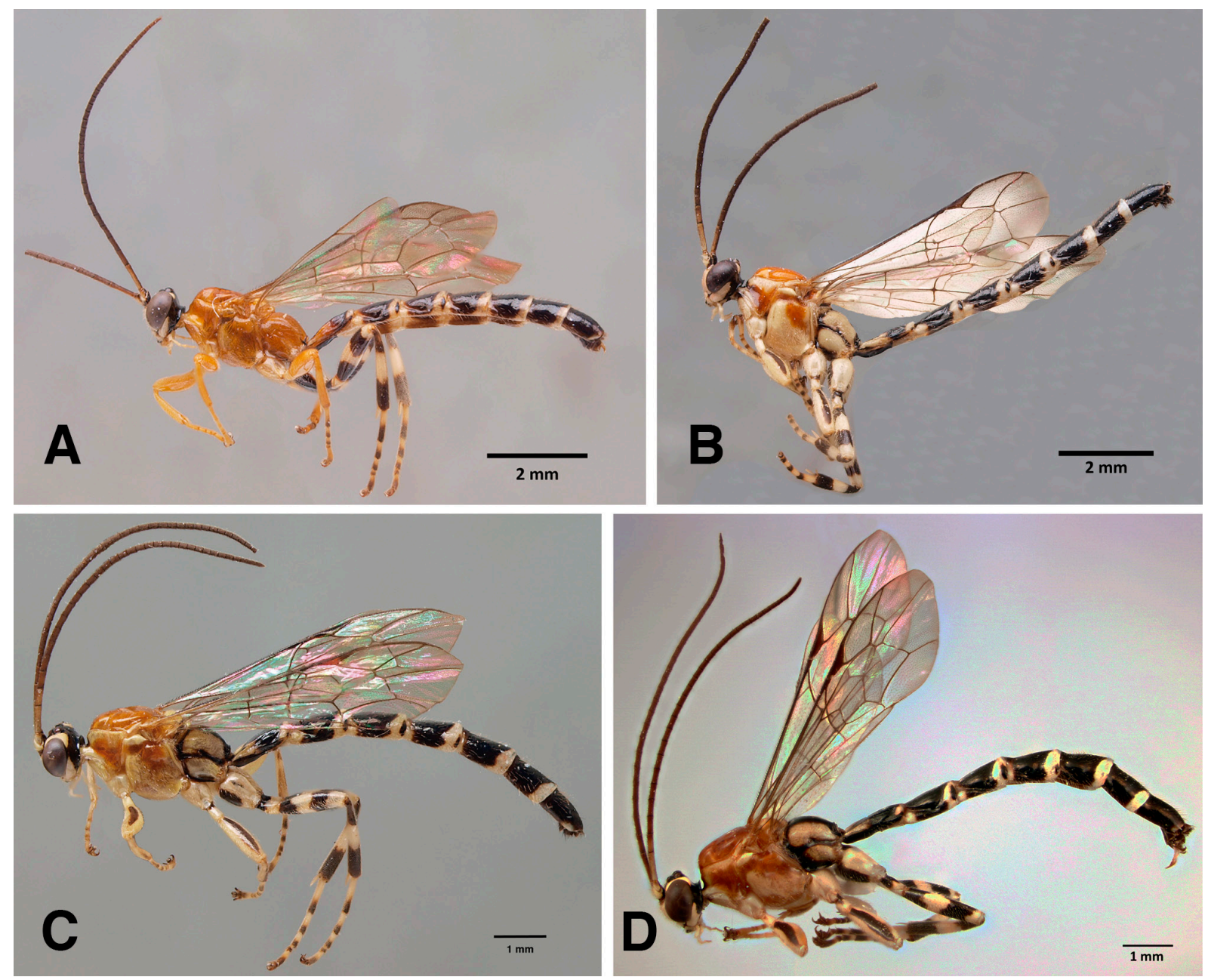

Fig. 10. Habitus of Clistopyga spp., ఏోð. A. Clistopyga orellanae Bordera \& Sääksjärvi sp. nov., holotype. B. C. yabuquensis González-Moreno, Bordera \& Sääksjärvi sp. nov., paratype. C. C. chaconi Gauld, 1991. D. C. mocaguae Palacio \& Bordera sp. nov., paratype. 
Colouration. Body primarily orange, black and white (Fig. 3B). Antenna brown with scape, pedicel, and basal flagellomeres in ventral part white. Head black, with ventral part of gena, basal half of mandible, inner eye orbit, two blotches under antennal insertions and two blotches on face white. Pronotum mostly orange, with anterior part yellow cream. Mesopleuron mostly orange, with anterior margin yellow cream. Metapleuron yellow cream, with ventral margin black. Mesoscutum mostly orange. Prescutellar groove orange. Scutellum mostly yellow, with apex whitish. Metanotum orange, with postscutellum white. Propodeum mostly white, with anterior margin, pleural groove and a broad central longitudinal stripe black. Tegula and subalar prominence white. Wings very weakly infumate, pterostigma black brown. Fore leg mostly yellow cream, with coxa ventrally and laterally black, femur dorsally dark brown to black and apical part of tarsomeres infuscate. Mid leg predominantly white, with femur and tibia black striped dorsally, and apical part of tarsomeres infuscate. Hind leg white, with coxa anteriorly and posteriorly, trochanter proximally, femur proximally and subdistally and tibia proximally and distally black, tarsomeres with distal apices black. Metasoma black, with anterior corners of tergites I-IV(V) and posterior margins of all tergites white. Ovipositor reddish brown. Ovipositor sheath black.

Male (Figs 10D, 11D, F)

Similar to female but body length $11.5 \mathrm{~mm}$; fore wing length $6.5 \mathrm{~mm}$; hind femur about 3.7 times as long as deep; tergite I 1.9 times as long as posteriorly broad; lateromedian longitudinal carina reaching about 0.5 of length of tergite; tergite II 1.35 times as long as posteriorly broad.

Colouration. Similar in colour to female but face completely white (Fig. 11D); white areas on mesoscutum, scutellum, pronotum and mesonotum more extensive; coxae and trochanters of fore and mid legs completely white (Fig. 10D).

\section{Distribution}

Colombia.

Clistopyga orellanae Bordera \& Sääksjärvi sp. nov. urn:1sid:zoobank.org:act:77380D06-EE80-4C2F-8E82-467C1A8797D2

Figs 10A, 11A

\section{Diagnosis}

Clistopyga orellanae sp. nov. can be distinguished from all other species of the $C$. chaconi species group with known males by the combination of the following characters: propodeum and metapleuron entirely orange (Fig. 10A); tergite I orange and black (Fig. 10A); face with very fine and sparse setiferous punctures (Fig. 11A); first flagellomere about 6.7 times as long as wide. C. orellanae sp. nov. resembles females of C. misionensis sp. nov. and C. rondoniae sp. nov. in colouration and structure. It is close to $C$. misionensis sp. nov. by possessing hyaline wings with a yellowish tint, mesosoma orange, hind coxa dorsally white, ventrally dark brown to black (Fig. 10A), occipital carina moderately raised, forming a flat dorsomedial flange, slightly upcurved posteriorly and epicnemial carina weak and ending considerably below level of centre of pronotum. However, it differs in having the face with very fine and sparse setiferous punctures, clypeal suture strongly curved (Fig. 11A) and tergites IV-VI with the dark brown area not extending backward laterally into the white posterior band (Fig. 10A). On the other hand, it is close to $C$. rondoniae sp. nov. by possessing mesonotum orange, hind coxa dorsally white, ventrally dark brown to black, tergites IV-VI with the dark brown area not extending laterally backward on the posterior white band (Fig. 10A) and clypeal suture strongly curved (Fig. 11A). However, it differs in having hyaline wings with a yellowish tint, face with very fine and sparse setiferous punctures (Fig. 11A), epicnemial carina present and occipital carina forming a flat dorsomedial flange, slightly upcurved posteriorly. 

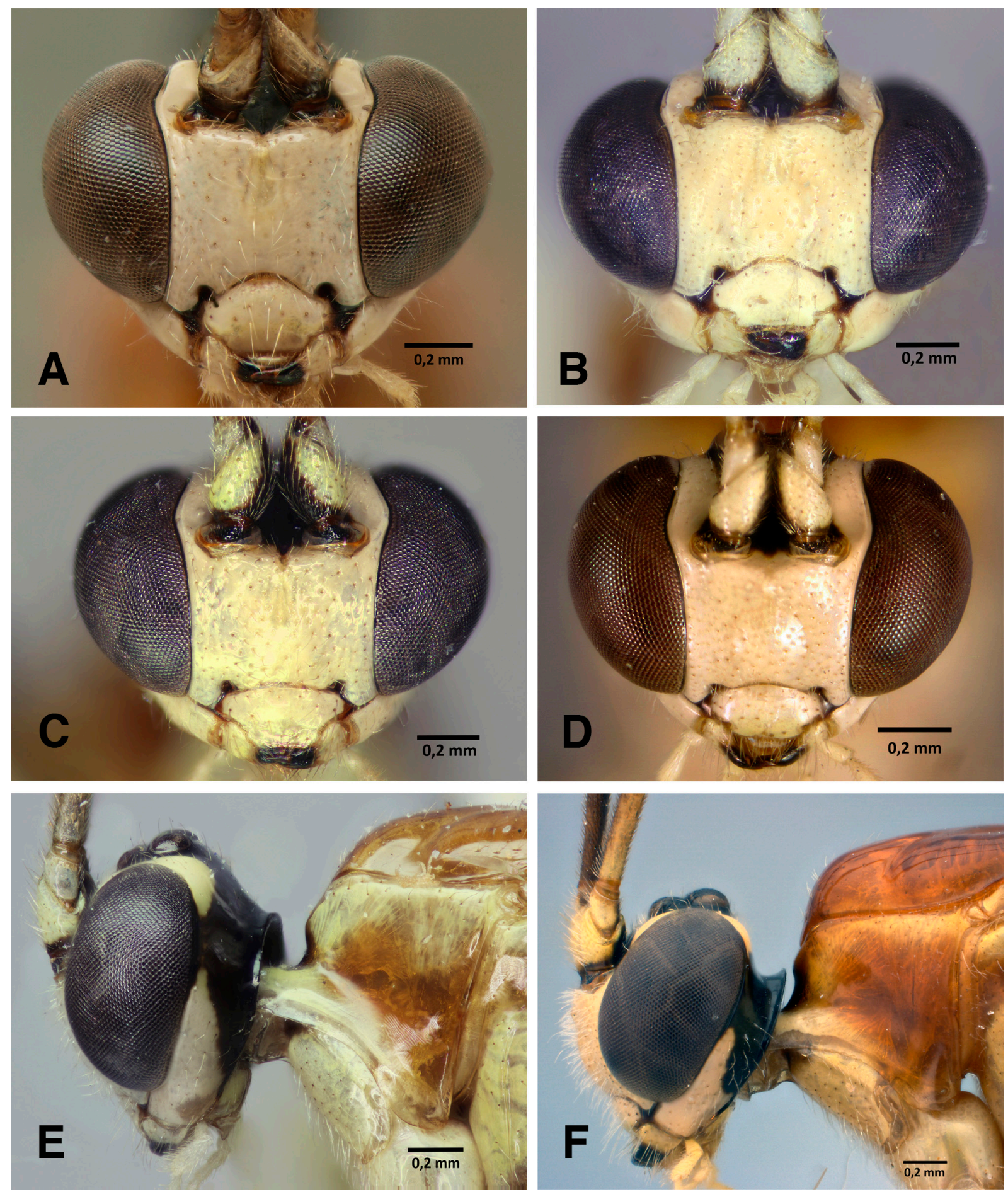

Fig. 11. Morphology of Clistopyga spp., ồ - - A-D. Head, frontal view. A. Clistopyga orellanae Bordera \& Sääksjärvi sp. nov., holotype. B. C. yabuquensis González-Moreno, Bordera \& Sääksjärvi sp. nov., paratype. C. C. chaconi Gauld, 1991. D. C. mocaguae Palacio \& Bordera sp. nov., paratype. E-F. Head and pronotum, lateral view. E. C. chaconi Gauld, 1991. F. C. mocaguae Palacio \& Bordera sp. nov., paratype. 
BORDERA S. et al., The species of the Clistopyga chaconi species-group

\section{Etymology}

The name of the species refers to the area where the holotype was collected, Department of Orellana, Ecuador.

\section{Material examined}

\section{Holotype}

ECUADOR: ${ }^{\top}$, Dept. of Orellana, Onkone Gare, $0^{\circ} 39^{\prime} 25.7^{\prime \prime} \mathrm{S}, 76^{\circ} 27^{\prime} 10.8^{\prime \prime} \mathrm{W}, 216.3 \mathrm{~m}$, canopy fogging, 22 Oct. 2005, coll. T. L. Erwin et al. (ZMUT).

\section{Description}

\section{Male}

MEAsurements. Body length $9 \mathrm{~mm}$. Fore wing length $6 \mathrm{~mm}$.

HEAD. In dorsal view, strongly narrowed behind eyes. Gena smooth and shiny, with sparse, moderately long setae ventrally, in dorsal view 0.4 times as long as eye, in frontal view straight and moderately constricted below eyes (Fig. 11A). Frons smooth and shiny, with a weak medial longitudinal depression. Vertex smooth and shiny, with very isolated setiferous punctures. Posterior ocellus separated from eye about 0.7 times its maximum diameter. Distance between hind ocelli about 0.9 times maximum diameter of posterior ocellus. Occipital carina moderately raised, forming a relatively short, flat dorsomedial flange, slightly upcurved posteriorly. Occiput in dorsal view straight. Face with very fine and sparse setiferous punctures. Clypeal suture strongly curved. Clypeus about 1.7 times as broad as long medially. Malar space about 0.8 times as long as basal mandibular width (Fig. 11A). Antenna with 33 flagellomeres, first flagellomere about 6.7 times as long as wide.

Mesosoma. Pronotum shiny, mostly smooth, with very fine and sparse setiferous punctures in upper posterior part. Epomia absent. Mesoscutum entirely smooth and shiny, median lobe anteriorly with very few, shallow and sparse setiferous punctures, posterior end of median lobe not prominent. Notauli weak, reaching about 0.4 of length of mesoscutum. Mesopleuron shiny, mostly smooth, with very sparse and fine setiferous punctures except in dorsal and lateral posterior part. Epicnemial carina weak, its dorsal end weakly curved backward, ending moderately far from anterior margin of mesopleuron, considerably below level of centre of pronotum. Metapleuron smooth and shiny, with fine and sparse setiferous punctures on dorsal posterior part, about 1.7 times as long as deep. Propodeum smooth and shiny, with sparse and fine setiferous punctures laterally; in dorsal view about 1.0 times as long as medially wide. Propodeal spiracle situated immediately above groove separating propodeum and metapleuron. Hind leg with femur 3.85 times as long as deep, about 0.8 times as long as tibia. Fore wing with vein $\mathrm{Cu}-a$ opposite $R s \& M$. Vein $2 r s-m$ clearly shorter than half length of abscissa of $M$ between $2 r s-m$ and $2 m-c u$. Abscissa of $C u 1$ between $1 m-c u$ and $C u 1 a$ about 3.0 times as long as $C u 1 b$. Hind wing with vein $c u-a$ about 0.3 times as long as abscissa of $C u 1$ between $M$ and $c u-a$; vein $c u-a+$ abscissa of Cu1 between M and $c u-a$ slightly reclivous. Vein $C u 1$ distinctly pigmented.

Metasoma. Tergite I about 1.85 times as long as posteriorly broad, smooth and shiny, with very fine, sparse setiferous punctures laterally; spiracle near its basal 0.35 ; lateromedian longitudinal carinae strong, reaching about 0.4 of length of tergite; lateral longitudinal carina absent. Sternite I extending back about 0.55 of length of tergite. Tergite II about 1.25 times as long as posteriorly broad, central region shiny, with isolated fine setiferous punctures; rest of tergites shiny, somewhat more densely punctate.

Colouration. Body primarily orange, black and white (Figs 10A, 11A). Antenna brownish, pallid towards base of external side including pedicel, distal rim of scape yellow. Head with vertical and frontal orbits, face, clypeus, base of mandible and ventral part of gena white; rest of frons and vertex, upper part of gena and occiput black. Palpi orange. Mesosoma entirely orange except dorsal posterior border 
of propodeum black. Tegula orange. Wings hyaline with a slightly yellow tint, pterostigma brown. Fore legs orange. Mid leg mostly orange, with distal part of tarsomeres dark brown. Hind leg mostly black, with coxa dorsally, trocantellus, central and distal bands of femur, wide band in middle of tibia and proximal part of tarsal segments white. Metasoma dark brown to black, anterior corners of tergites I-IV and posterior band of tergites I-VII white; posterior corners of tergites I-III with black spots; anterior part of tergite I tinged with orange.

\section{Female}

Unknown.

\section{Distribution}

Ecuador.

Clistopyga porteri Bordera \& Sääksjärvi sp. nov. urn:Isid:zoobank.org:act:5AF411B0-1213-4CB2-9FFA-F429D28F707C

Figs 3D, 6B, D, F

\section{Diagnosis}

Clistopyga porteri sp. nov. can be distinguished from all other species of the $C$. chaconi species group by the combination of the following characters: wings very weakly infuscate; propodeum and metapleuron black and yellow; mesopleuron and mesosternum orange (Fig. 3D); clypeal suture strongly curved (Fig. 6B); tergite II 1.3 times as long as broad; metapleuron about 2.0 times as long as deep; antenna with 36 flagellomeres; epicnemial carina very weak, ending considerably below level of centre of pronotum; hind wing with vein $c u-a+$ abscissa of $C u 1$ between $M$ and $c u-a$ strongly reclivous (Fig. 6D); gena, in frontal view, straight and moderately constricted below eyes (Fig. 6B); ovipositor weakly and evenly upcurved over apical 0.5 (Fig. 6F).

\section{Etymology}

The name of the species refers to the late Charles Porter, one of the pioneers of Neotropical ichneumonology.

\section{Material examined}

\section{Holotype}

ARGENTINA: + , Cataratas Misiones, 6 Nov. 1970, coll. C. Porter (FSCA).

\section{Description}

\section{Female}

MeAsurements. Body length $11 \mathrm{~mm}$. Fore wing length $8 \mathrm{~mm}$

HEAD. In dorsal view, strongly narrowed behind eyes. Gena smooth and shiny, with sparse, moderately long setae ventrally, in dorsal view about 0.4 times as long as eye, in frontal view straight and moderately constricted below eyes (Fig. 6B). Frons smooth and shiny, with a weak medial longitudinal groove. Vertex smooth and shiny, with very isolated setiferous punctures. Posterior ocellus separated from eye about 0.8 times its maximum diameter. Distance between hind ocelli about 1.0 times maximum diameter of posterior ocellus. Occipital carina strongly raised, forming a dorsomedial flange, conspicuously upcurved posteriorly. Face strongly and densely punctate, distance between punctures about diameter of punctures. Clypeal suture strongly curved. Clypeus 1.8 times as broad as medially long, weakly convex in dorsal half, flat in ventral half, with apical margin truncate. Malar space 0.87 times as long as basal mandibular width, with deep and narrow sulcus between eye and mandible, sulcus short, 
evanescent towards mandibular base, forming a wide triangular granulate area (Fig. 6B). Antenna with 36 flagellomeres, first flagellomere about 6.2 times as long as wide.

Mesosoma. Pronotum shiny, mostly smooth, with fine and sparse setiferous punctures in upper posterior part. Mesoscutum entirely smooth and shiny, median lobe anteriorly with very fine and sparse setiferous punctures. Notauli shallow, reaching about half of length of mesoscutum. Mesopleuron shiny, mostly smooth, with very sparse and fine setiferous punctures, except in dorsal posterior part. Epicnemial carina very weak, its dorsal end far from anterior margin of mesopleuron, considerably below level of centre of pronotum. Metapleuron smooth and shiny, with fine and sparse setiferous punctures, about 2.0 times as long as deep. Propodeum smooth and shiny, with sparse and fine setiferous punctures laterally; in dorsal view about 1.0 times as long as medially wide. Propodeal spiracle situated immediately above groove separating propodeum and metapleuron. Hind leg with femur about 3.6 times as long as deep, 0.9 times as long as tibia. Fore wing with vein $c u-a$ opposite $R s \& M$. Vein $2 r s-m$ shorter than half length of abscissa of $M$ between $2 r s-m$ and $2 m-c u$. Abscissa of $C u 1$ between $1 m-c u$ and $C u 1$ a about 1.8 times as long as $C u 1 b$. Hind wing with vein $c u-a 0.55$ times as long as abscissa of $C u 1$ between $M$ and $c u-a$. Vein $c u-a+$ abscissa of $C u 1$ between $M$ and $c u-a$ strongly reclivous. Vein $C u 1$ distinctly pigmented.

Metasoma. Tergite I about 1.8 times as long as posteriorly broad, smooth and shiny, with very fine, sparse setiferous punctures laterally and posteriorly; spiracle near its basal 0.3 ; lateromedian longitudinal carinae strong, reaching about 0.2 of length of tergite; lateral longitudinal carinae absent. Sternite I extending back about 0.6 of length of tergite. Tergite II 1.3 times as long as posteriorly broad, central region shiny, with fine and moderately dense setiferous punctures; rest of tergites shiny, more densely and strongly punctate. Ovipositor slender, weakly and evenly upcurved at distal 0.5 (Fig. 6F), matt, 1.35 times as long as hind tibia. Ovipositor sheath about 1.0 times as long as hind tibia, length of setae on average about twice sheath basal width (Fig. 6F).

Colouration. Body primarily orange, black and white (Fig. 3D). Antenna brown, with scape, pedicel and basal flagellomeres in ventral part white. Head black, with clypeus, base of mandibles, ventral part of gena and inner eye orbit, two longitudinal blotches on face and two transverse blotches under antennal sockets white. Palpi yellow. Propleuron orange, with dorsal part and ventral margin infuscate. Pronotum mostly orange, with anterior margin yellow. Mesopleuron orange, with subalar prominence, posterior margin and posterior ventral corner yellow. Mesosternum orange. Metapleuron yellow, with ventral part black. Mesoscutum and prescutellar groove orange. Scutellum light orange, yellow at apex. Metanotum orange, with postscutellum yellow. Propodeum mostly yellow, with anterior margin, pleural groove and a broad central longitudinal stripe black. Tegula light orange and yellow. Wings very weakly infuscate, pterostigma dark brown. Fore leg light orange, with basal and lateral parts of coxa, dorsal longitudinal stripe on femur and distal parts of tarsomeres dark brown. Mid leg predominantly yellowish, with distal ventral part of coxa, dorsal stripe on trochanter, femur, tibia and distal part of tarsomeres black. Hind leg predominantly yellow, with ventral half of coxa, base of trochanter, base and subdistal band on femur, basal and distal part of tibia, and distal part of tarsomeres dark brown to black. Metasoma dark brown to black, anterior corners of tergites I-III yellowish, posterior band of tergites I-V (VI) yellowish. Posterior corners of tergites I-III with black spots. Ovipositor brown. Ovipositor sheath black.

\section{Male}

Unknown.

\section{Distribution}

Argentina. 
Clistopyga rondoniae Bordera \& Sääksjärvi sp. nov. urn:1sid:zoobank.org:act:7428E633-DF14-4358-8EB1-B887A66A6835

Figs 7B, 8B, D, F

\section{Diagnosis}

Clistopyga rondoniae sp. nov. can be distinguished from all other species of the C. chaconi species group by the combination of the following characters: wings entirely and moderately infuscate; propodeum and metapleuron entirely orange; hind coxa dorsally white, ventrally dark brown to black; tergites IVVI with the dark brown area not extending laterally backward into the posterior white band (Fig. 7B); clypeal suture strongly curved (Fig. 8D); occipital carina strongly raised, forming a dorsomedial flange, conspicuously upcurved posteriorly (Fig. 8B); epicnemial carina absent; ovipositor stout, strongly upcurved over apical 0.4 (Figs 7B, 8F).

\section{Etymology}

The name of the species refers to the area where the holotype was collected, Rondonia State, Brazil.

\section{Material examined}

\section{Holotype}

BRAZIL: ㅇ, Vilhena (Rondonia State), Nov. 1973 (AEIC).

\section{Description}

\section{Female}

Measurements. Body length $10 \mathrm{~mm}$. Fore wing length $7 \mathrm{~mm}$.

HEAD. In dorsal view, strongly narrowed behind eyes. Gena smooth and shiny, with sparse, moderately long setae ventrally, in dorsal view 0.4 times as long as eye, in frontal view straight and moderately constricted below eyes (Fig. 8D). Frons smooth and shiny, with a weak medial longitudinal depression. Vertex smooth and shiny, with very isolated setiferous punctures. Posterior ocellus separated from eye by about 0.8 times its maximum diameter. Distance between hind ocelli about 0.8 times maximum diameter of posterior ocellus. Occipital carina strongly raised, forming a dorsomedial flange, conspicuously upcurved posteriorly (Fig. 8B). Face strongly and densely punctate, distance between punctures about diameter of punctures. Clypeal suture strongly curved. Clypeus 1.6 times as broad as medially long, weakly convex in dorsal half, flat in ventral half, with apical margin truncate. Malar space about 0.8 times as long as basal mandibular width, with deep and narrow sulcus between eye and mandible, sulcus short, evanescent towards mandibular base, forming a wide triangular granulate area (Fig. 8D). Antenna of unique holotype broken, with 31+ flagellomeres, first flagellomere about 4.6 times as long as wide.

Mesosoma. Pronotum shiny, mostly smooth, with very fine and sparse setiferous punctures in upper posterior part. Mesoscutum entirely smooth and shiny, median lobe anteriorly with very few shallow and sparse setiferous punctures. Notauli weak, reaching about 0.4 of length of mesoscutum. Mesopleuron shiny, mostly smooth, with very sparse and fine setiferous punctures except in dorsal and lateral posterior part. Epicnemial carina absent. Metapleuron smooth and shiny, with fine and sparse setiferous punctures on dorsal posterior part, about 2.0 times as long as deep. Propodeum smooth and shiny, with sparse and fine setiferous punctures laterally; in dorsal view about 0.95 times as long as medially wide. Propodeal spiracle situated immediately above groove separating propodeum and metapleuron. Hind leg with femur 3.6 times as long as deep, 0.9 times as long as tibia. Fore wing with vein $c u$ - $a$ opposite $R s \& M$. Vein $2 r s-m$ shorter than half length of abscissa of $M$ between $2 r s-m$ and $2 m-c u$. Abscissa of $C u 1$ between $1 m-c u$ and $C u 1$ a about 3.0 times as long as $C u 1$ b. Hind wing with vein $c u-a$ about 0.4 times as long as 
abscissa of $C u 1$ between $M$ and $c u-a$. Vein $c u-a+$ abscissa of $C u 1$ between $M$ and $c u-a$ vertical. Vein $\mathrm{Cu} 1$ distinctly pigmented.

Metasoma. Tergite I about 1.7 times as long as posteriorly broad, smooth and shiny, with very fine, sparse setiferous punctures laterally; spiracle near its basal 0.4 ; lateromedian longitudinal carinae strong, reaching about 0.2 of length of tergite; lateral longitudinal carina absent. Sternite I extending back about 0.6 of length of tergite. Tergite II 1.2 times as long as posteriorly broad, central region shiny, with shallow and dense punctures; rest of tergites shiny, more densely punctate. Ovipositor stout, strongly upcurved in apical 0.4 , matt, 1.25 times as long as hind tibia. Ovipositor sheath about 0.94 times as long as hind tibia, length of setae on average about 1.5 times sheath basal width.

Colouration. Body primarily orange, black and white (Fig. 7B). Antenna brownish, pallid towards base of external side including pedicel, distal rim of scape yellow. Head black with clypeus, base of mandible, ventral part of gena, inner eye orbit, two longitudinal blotches on the face and two transverse blotches under antennal sockets white. Palpi orange. Mesosoma entirely orange except dorsal posterior border of propodeum black. Tegula orange. Wings entirely and moderately infuscate, pterostigma brown. Fore legs orange. Mid leg mostly orange, with ventral part of coxa and posterior part of trochanter dark brown to black. Hind leg black, coxa dorsally, femur distally and centrally (non-defined band), wide band in middle of tibia and proximal part of tarsal segments white. Metasoma dark brown to black, anterior corners of tergites I-IV and posterior band of tergites I-VII white. Posterior corners of tergites I-III with black spots. Ovipositor dark brown. Ovipositor sheath black.

\section{Male \\ Unknown.}

\section{Distribution}

Brazil.

Clistopyga yabuquensis González-Moreno, Bordera \& Sääksjärvi sp. nov.
urn:lsid:zoobank.org:act:5215A6F2-B714-4E79-8C33-B24ACA90E68E

Figs 3C, 6A, C, E, 10B, 11B

\section{Diagnosis}

Clistopyga yabuquensis sp. nov. can be distinguished from all other species of the C. chaconi species group by the combination of the following characters: wings hyaline, propodeum and metapleuron black and white; mesopleuron ventrally and mesosternum yellow (Figs 3C, 10B); clypeal suture strongly curved (Figs 6A, 11B). Female with tergite II 1.3-1.4 times as long as broad; metapleuron 1.8-1.9 times as long as deep; antenna with 35-36 flagellomeres; epicnemial carina strong, reaching level of centre of pronotum; hind wing with vein $c u-a+$ abscissa of $C u 1$ between $M$ and $c u-a$ vertical (Fig. 6C); gena, in frontal view, slightly rounded and strongly constricted below eyes (Fig. 6A); ovipositor sinuous and slightly upcurved over apical 0.4 (Fig. 6E). Male with face strongly and densely punctate (Fig. 11B); first flagellomere 5.45 times as long as wide; hind femur about 4.2 times as long as deep.

\section{Etymology}

The name of the species refers to the area where the holotype was collected, Yabucu, Mexico.

\section{Material examined}

Holotype

MEXICO: + , Yucatán State, Seye, Yabucu, Malaise trap, 28 Sep. 2014, coll. A. González (CEUA). 
Paratypes

MEXICO: 2 우, same data as holotype, 9 Oct. 2014 and 14 Nov. 2015 (CEUA); $1 \hat{\jmath}$, same state and collector, Río Lagartos, Sabana, Poste 024, Malaise trap, 10-23 Dec. 2008 (CEUA) (reported as C. chaconi in Bordera et al. 2014).

\section{Description}

\section{Female}

MEASUREMEnTs. Body length $12 \mathrm{~mm}$. Fore wing length 7-8 mm.

HEAD. In dorsal view, strongly narrowed behind eyes. Gena smooth and shiny, with sparse, moderately long setae ventrally, in dorsal view $0.4-0.5$ times as long as eye, in frontal view slightly rounded and strongly constricted below eyes (Fig. 6A). Frons smooth and shiny, with a weak medial longitudinal hollow. Vertex smooth and shiny, with very isolated setiferous punctures. Posterior ocellus separated from eye about $0.7-0.8$ times its maximum diameter. Distance between hind ocelli $0.85-1.0$ times maximum diameter of posterior ocellus. Occipital carina strongly raised, forming a dorsomedial flange, conspicuously upcurved posteriorly. Face strongly and densely punctate, distance between punctures about diameter of punctures. Clypeal suture strongly curved. Clypeus 1.7-2.4 times as broad as medially long, weakly convex in dorsal half, flat in ventral half, with apical margin truncate. Malar space $0.75-0.9$ times as long as basal mandibular width, with a deep, narrow, smooth and shiny sulcus between eye and mandible (Fig. 6A). Antenna with 35-36 flagellomeres, first flagellomere 5.4-6.3 times as long as wide.

Mesosoma. Pronotum shiny, mostly smooth, with fine and sparse setiferous punctures in upper posterior part. Mesoscutum entirely smooth and shiny, median lobe anteriorly with very fine, shallow and sparse setiferous punctures. Notauli shallow, reaching about 0.4 of length of mesoscutum. Mesopleuron shiny, mostly smooth, with very sparse and fine setiferous punctures except in dorsal posterior part. Epicnemial carina strong, its dorsal end far from anterior margin of mesopleuron, ending at level of centre of pronotum. Metapleuron smooth and shiny, with fine and sparse setiferous punctures, 1.8-1.9 times as long as deep. Propodeum smooth and shiny, with sparse and fine setiferous punctures laterally; in dorsal view $0.90-0.95$ times as long as medially wide. Propodeal spiracle situated immediately above groove separating propodeum and metapleuron. Hind leg with femur 3.7-3.8 times as long as deep, 0.80.9 times as long as tibia. Fore wing with vein $c u-a$ opposite $R s \& M$. Vein $2 r s-m$ longer than half length of abscissa of $M$ between $2 r s-m$ and $2 m-c u$. Abscissa of $C u 1$ between $1 m-c u$ and $C u 1$ a 1.5-1.6 times as long as $C u 1 \mathrm{~b}$. Hind wing with vein $c u-a$ 0.4-0.5 times as long as abscissa of $C u 1$ between $M$ and $c u-a$. Vein $c u-a+$ abscissa of $C u 1$ between $M$ and $c u-a$ vertical (Fig. 6C). Vein $C u 1$ distinctly pigmented.

Metasoma. Tergite I 1.67-1.75 times as long as posteriorly broad, smooth and shiny, with very fine, sparse setiferous punctures laterally and posteriorly; spiracle near its basal 0.4; lateromedian longitudinal carinae strong, reaching about 0.2 of length of tergite; lateral longitudinal carinae strong, reaching about 0.2 of length of tergite. Sternite I extending back about 0.5 of length of tergite. Tergite II 1.3-1.4 times as long as posteriorly broad, central region shiny, with fine and moderately sparse setiferous punctures; rest of tergites shiny, more densely and strongly punctate. Ovipositor slender, sinuous and slightly upcurved over apical 0.4, matt, 1.2-1.45 times as long as hind tibia (Figs 3C, 6E). Ovipositor sheath 0.9-1.1 times as long as hind tibia, length of setae on average 2.0-2.4 times sheath basal width (Fig. 6E).

Colouration. Body primarily orange, black and white (Fig. 3C). Antenna brown with scape, pedicel, and basal flagellomeres in ventral part white. Head black, with clypeus, basal half of mandible, ventral part of gena and inner eye orbit white. Face from dark brown (with a white band below antennal sockets and two longitudinal blotches) to entirely white, with a median dark spot. Palpi white. Propleuron white, dorsally black. Pronotum mostly orange, with anterior and dorsal margin white, dorsal anterior part 
infuscate. Mesopleuron mostly yellow, with a large dorsal orange mark below subalar prominence. Mesosternum yellow. Metapleuron white, with ventral part black. Mesoscutum and prescutellar groove orange. Scutellum yellow, centrally orange, sometimes with apex white. Metanotum black, with postscutellum white. Propodeum mostly white, with anterior margin, pleural groove and a broad central longitudinal band black. Tegula orange. Wings hyaline, pterostigma dark brown. Fore leg and mid leg predominantly white, with coxae ventrally in part, dorsal stripe on trochanters, femora, tibiae and distal part of tarsomeres black. Hind leg white, with coxa ventrally, trochanter, femur proximally and subdistally, tibia proximally and distally and distal part of tarsomeres black. Metasoma black, with anterior corners of tergites I-V and posterior band of tergites I-VII white; posterior corners or margins of tergites I-III black. Ovipositor light brown. Ovipositor sheath black.

Male (Figs 10B, 11B)

As female, but body length $11 \mathrm{~mm}$, fore wing length $6 \mathrm{~mm}$. Gena in dorsal view about 0.35 times as long as eye, in frontal view slightly rounded and strongly constricted below eyes (Fig. 11B). Posterior ocellus separated from eye about 0.9 times its maximum diameter. Malar space as long as basal mandibular width, with deep and narrow sulcus between eye and mandible, evanescent towards mandibular base, forming a wide triangular granulate area (Fig. 11B). Antenna broken in single available specimen, with at least 19 flagellomeres. Metapleuron about 1.70 times as long as deep. Hind leg with femur 4.2 times as long as deep, 0.84 times as long as tibia. Abscissa of $C u 1$ between $1 \mathrm{~m}$-cu and $\mathrm{Cu}$ 1a about 1.75 times as long as $C u 1 b$. Tergite I about 1.9 times as long as posteriorly broad, lateral longitudinal carinae strong, reaching about 0.4 of length of tergite. Sternite I extending back about 0.6 of length of tergite. Tergite II about 1.4 times as long as posteriorly broad.

Colouration. As in female, but face entirely yellow (Fig. 11B), metapleuron more extensively yellow marked, fore and mid coxa and fore trochanter entirely yellow; hind coxa with anterior and posterior black marks. Black posterior marks of metasomal tergites present from tergites I to IV (Fig. 10B).

\section{Distribution}

Mexico.

\section{Discussion}

The genus Clistopyga is currently represented by 49 described species in the world (including the species here described as new). Most of the species belong to the calixtoi species group, which includes all the "typical" Clistopyga species with an apically upcurved and finely coriaceous ovipositor. The other species group is represented by some Neotropical and Afrotropical species, most of them currently undescribed, which Gauld (1991) placed in his henryi species group. All henryi species share a long, straight and polished ovipositor. Gauld (1991) also briefly discussed the generic placement of the group, which is not yet certain.

In the present form, the calixtoi species group includes a morphologically diverse set of species. In the current study, we diagnosed a new species group, the chaconi group, separated it from the traditional calixtoi group and placed 13 species in total in this group. All species of the new group are characterized by a strong occipital carina, which is raised into a flange-like protuberance.

The flange-like occipital carina is rare within the parasitoid wasp family Ichneumonidae. In the subfamily Pimplinae it is present at least in most species of Acrotaphus Townes, 1960, Hymenoepimecis Viereck, 1912 and Ticapimpla Gauld, 1991 and in some species of Eriostethus Morley, 1914 and Xanthopimpla Saussure, 1892. In addition, we have seen some Neotropical species of campoplegines and cryptines with an occipital flange (Sääksjärvi, unpublished data). It is interesting that most ichneumonids possessing a flange-like occipital carina are tropical and many of them are associated with spiders. 
Gauld (1991) briefly discussed the function of cuticular processes as defensive structures. He proposed that the occipital flange could protect the cervical membrane against attacks by asilid flies, but it remains unknown, whether there is a relationship between this structure and the spider-parasitizing habit of these ichneumonids.

In the present study, we described 11 new species of Clistopyga from Mexico and Central and South America. The high number of new species, in fact doubling the number of Clistopyga species known from the vast continent of South America, shows that a lot of effort is needed in studying this genus. Clistopyga species are rare in collections. It may actually be rare in nature or just hard to collect using common methods employed in sampling ichneumonids (Bordera et al. 2014). We aim to continue the study of tropical Clistopyga and will describe a plethora of new species found during extensive field studies conducted by us in several parts of the New and Old World tropics.

\section{Acknowledgements}

The authors are grateful to Dr. David Wahl and Dr. Hugo Kons from AEIC, Dr. Ronald Zuniga and Dr. Manuel Solis from INBio, Dr. Jim Wiley from FSCA, Dr. Gavin Broad from BMNH and Dr. Claudia Medina form IAVH for permitting us to study material preserved in their respective institutions. Dr. Kari Kaunisto (ZMUT) helped with part of the layer images. We would also like to thank the two anonymous referees for their valuable comments on the manuscript. This study was partially supported by the projects "El valor de las Reservas Privadas en la conservación de la diversidad de insectos parasitoides" (Instituto Tecnológico Nacional de México, Code: 5554.15-P) and "Biodiversity and multitrophic interactions" (Kone Foundation, Finland).

\section{References}

Bordera S., González-Moreno A., Khalaim A.I. \& Sääksjärvi I.E. 2014. Revision of North American species of Clistopyga (Hymenoptera: Ichneumonidae: Pimplinae). The Canadian Entomologist 146: 355-414. http://dx.doi.org/10.4039/tce.2013.74

Eady R.D. 1968. Some illustrations of microsculpture in the Hymenoptera. Proceedings of the Royal Entomological Society of London (A) 43: 66-72.

Gauld I.D. 1991. The Ichneumonidae of Costa Rica, 1. Memoirs of the American Entomological Institute 47: $1-589$.

Nielsen E. 1929. A second supplementary note upon the life histories of the Polysphinctas (Hym. Ichneum.). Entomologiske Meddelelser 16: 366-368.

Porter C.C. (1979) Ichneumonidae de Tarapaca, I. Subfamilia Ephialtinae (Hymenoptera). Idesia 5: $157-187$.

Sääksjärvi I.E., Castillo C., Bordera S., Broad G.R., Rinne V. \& Fritzén N.R. 2015. Clistopyga caramba sp. nov. (Hymenoptera: Ichneumonidae; Pimplinae), an astonishing example of mimicry in spiderattacking parasitoid wasps. Zootaxa 4013 (2): 287-292. http://dx.doi.org/10.11646/zootaxa.4013.2.9

Varga O. \& Reshchikov A. 2015. New records of the genus Clistopyga Gravenhorst, 1829 (Hymenoptera: Ichneumonidae: Pimplinae) from the Oriental region, with description of a new species. Zootaxa 3964 (5): 561-568. http://dx.doi.org/10.11646/zootaxa.3964.5.6

Yu D.S., van Achterberg K. \& Horstmann K. 2012. World Ichneumonoidea 2012. Taxonomy, Biology, Morphology and Distribution. CD/DVD. Taxapad, Vancouver, Canada. http://www.taxapad.com 
Manuscript received: 14 December 2015

Manuscript accepted: 29 February 2016

Published on: 20 June 2016

Topic editor: Koen Martens

Desk editor: Kristiaan Hoedemakers

Printed versions of all papers are also deposited in the libraries of the institutes that are members of the EJT consortium: Muséum national d'Histoire naturelle, Paris, France; Botanic Garden Meise, Belgium; Royal Museum for Central Africa, Tervuren, Belgium; Natural History Museum, London, United Kingdom; Royal Belgian Institute of Natural Sciences, Brussels, Belgium; Natural History Museum of Denmark, Copenhagen, Denmark. 